FEDERAL RESERVE BANK OF SAN FRANCISCO

WORKING PAPER SERIES

\title{
Sellin' in the Rain: Weather, Climate, and Retail Sales
}

\author{
Brigitte Roth Tran \\ Federal Reserve Bank of San Francisco \\ January 2022 \\ Working Paper 2022-02 \\ https://www.frbsf.org/economic-research/publications/working-papers/2022/02/
}

\section{Suggested citation:}

Roth Tran, Brigitte. 2022 "Sellin' in the Rain: Weather, Climate, and Retail Sales," Federal Reserve Bank of San Francisco Working Paper 2022-02.

https://doi.org/10.24148/wp2022-02

The views in this paper are solely the responsibility of the authors and should not be interpreted as reflecting the views of the Federal Reserve Bank of San Francisco or the Board of Governors of the Federal Reserve System. 


\title{
Sellin' in the Rain: Weather, Climate, and Retail Sales
}

\author{
ROTH TRAN, BRIGITTE*
}

January 2022

\begin{abstract}
I apply a novel machine-learning based "weather index" method to daily storelevel sales data for a national apparel and sporting goods brand to examine short-run responses to weather and long-run adaptation to climate. I find that even when considering potentially offsetting shifts of sales between outdoor and indoor stores, to the firm's website, or over time, weather has significant persistent effects on sales. This suggests that weather may increase sales volatility as more severe weather shocks become more frequent under climate change. Consistent with adaptation to climate, I find that sensitivity of sales to weather decreases with historical experience for precipitation, snow, and cold weather events, but - surprisingly — not for extreme heat events. This suggests that adaptation may moderate some but not all of the adverse impacts of climate change on sales. Retailers can respond by adjusting their staffing, inventory, promotion events, compensation, and financial reporting.
\end{abstract}

Keywords: adaptation, climate change, weather, machine learning, retail, sales Keywords: Q54, L81, D12

${ }^{*}$ Roth Tran: Federal Reserve Bank of San Francisco, brigitte.rothtran@sf.frb.org. The views in this paper are those of the author and do not necessarily represent the views or policies of the Federal Reserve Bank of San Francisco or its staff. Acknowledgments: This material is based on work supported by the National Science Foundation under Grant No. 0903551. I thank Richard Carson, Julie Cullen, Glenn Folette, Stephie Fried, Dalia Ghanem, Joshua Graff Zivin, Bart Hobijn, Ivan Ivanov, Mark Jacobsen, Sarah Jacobson, Christopher Parsons, Ketki Sheth, Richard Sommerville, colleagues at the Federal Reserve Board and the Federal Reserve Bank of San Francisco. The paper benefited from comments and suggestions from seminar participants at U.C. San Diego, Resources for the Future, the Heartland Environment and Resource Economics Workshop 2018, the Federal Reserve Board, the Bureau of Labor Statistics, the Federal Deposit Insurance Commission, the Federal Housing and Finance Agency, and the Federal Reserve System Energy Workshop for helpful comments. I thank anonymous referees for their valuable feedback. Finally, I am grateful to Jack Mueller for excellent research assistance. 


\section{Introduction}

By increasing global temperatures and weather variability, ${ }^{1}$ climate change may have significant adverse impacts on the retail sector. Weather can make it difficult to get to stores, affect the experience of shopping and alternative activities (e.g., hiking or having a barbecue), and shift underlying demand for particular goods. Operating through channels like these, weather has the potential to affect firm profits, increase income volatility for workers, shift inventory needs, and muddle measures of staff and firm performance. There are several key challenges to understanding the impact of weather and climate on sales. First, simply examining immediate responses misses potentially important offsetting effects if sales shift across store types, to e-commerce, and over time. Second, weather is multi-dimensional, including temperature, precipitation, and snow. Third, responses to weather are heterogeneous, depending on season, region, and other contextual factors. Fourth, adaptation may reduce sensitivities of sales to weather events and thus eventually also the impacts of climate change on sales. Finally, examining adaptation requires highly granular high frequency data that spans a broad range of climates. This paper develops a novel empirical method to address these issues and estimate the effects of weather and climate on the sales of a major apparel and sporting good brand.

My analysis reveals two key results. First, I find that weather has significant and persistent effects on net sales. The immediate effects of weather are only slightly offset by sales shifting between store types or over time. This suggests that sales may become increasingly variable along with weather. Second, I find that sensitivity of retail sales to precipitation, snow, and cold weather declines with historical experience. In contrast, I surprisingly find no evidence that the negative effects of extreme heat events decrease with historical experience. Viewing climate adaptation as investments in physical and human capital that reduce the impacts of likely weather events, these results suggest

\footnotetext{
${ }^{1}$ For example, according to the 2018 National Climate Assessment, variability in precipitation is likely to increase (Hayhoe et al. (2018), p.88.)
} 
that adaptation may reduce the long-run effects on firm sales of some of the changing weather patterns expected under climate change - though not the projected increase in extreme heat events. ${ }^{2}$

Examining the relationship between climate and responses to weather requires data on outcomes that are frequent, detailed, and span a wide range of climates. I take advantage of a unique data set that has high spatial and temporal resolution and considerable variation in climates. My data consist of daily store-level sales observations for over 100 stores across the U.S. from April 2010 to December 2013. I am able to identify each store as "indoor" or "outdoor" based on whether it is in an indoor shopping center in which patrons move between stores without being exposed to the elements. ${ }^{3}$ In addition, I use weekly Metropolitan Statistical Area (MSA)-level sales at the firm's website to analyze shifting of sales from stores to e-commerce. Finally, I use contemporaneous and historical observations of daily temperature (minimum, maximum, and average), precipitation, snowfall, and snow depth from weather stations.

Estimating weather effects is challenging due to the multi-dimensionality of weather and heterogeneity of responses (which is driven in part by adaptation). A key contribution of this paper is a novel "weather index" that I develop to estimate the dynamics of short-run responses to generic weather shocks. In modeling weather, there is generally a trade-off between developing easily-interpreted results that reflect general dynamics and capturing the underlying complexity of how weather impacts sales. Factors like store type, location, time of year, and other aspects of weather (e.g., temperature) can determine if a given event (e.g., one inch of precipitation) is good, somewhat bad, or terrible for sales. I use the lasso machine learning method (with cross-validation) to construct a weather index that provides a one-dimensional summary measure of the

\footnotetext{
${ }^{2}$ For intuition, consider a store in an area accustomed to significant snow. Quick plowing of streets, pervasive use of snow tires, ample experience with driving in snow, and widespread use of snow boots could allow business to carry on much as usual in response to a moderate amount of snow. In contrast, a region highly unaccustomed to snow might shut down after very small amounts of it.

${ }^{3}$ Although an indoor store reduces the exposure to weather during an extended shopping trip involving visits to multiple stores, it does not eliminate the impact of weather entirely. Shoppers will often still be exposed to weather when traveling to the indoor shopping center, including potentially when going from a car in a parking lot to the store.
} 
weather shock on a given day at a given store. With a mean of zero and standard deviation of one, the index predicts how favorable weather conditions are for sales after accounting for a set of seasonal and store-specific controls. The higher the value, the more favorable the weather conditions are for sales. I then use the weather index to estimate the dynamics of short-run responses to generic weather shocks, asking, for example, how sales respond over time to a negative shock.

The weather index has several key advantages over standard non-parametric temperature and precipitation regressions. First, it collapses multiple dimensions of weather into one, facilitating interpretation. Second, the index incorporates heterogeneity in a tractable manner. Third, the weather index agnostically selects the aspects of weather most relevant to a given outcome, capturing important complexity while limiting overfitting of data. To combine the results from more standard methods into one-dimensional shocks, one would first have to decide how much complexity to include in the underlying analysis. A simple model likely misses important heterogeneity and non-linearity, while a very complex model likely overfits the data. By using the lasso with cross-validation, my weather index agnostically selects among a very large set of potential variables those most predictive (out-of-sample) of contemporaneous, immediate effects. ${ }^{4,5}$ In short, for questions on the general dynamics of responses to weather shocks, the weather index simultaneously yields results that are easily interpreted and capture appropriate underlying complexity.

Using the weather index to examine the dynamics of short-run responses to weather, I find that only a small share of immediate effects of weather shocks are offset through shifts in sales between indoor and outdoor stores and over time. Although precipitation and extreme heat shifts some sales from stores located in outdoor shopping centers to stores in indoor malls, on average, only about $1 / 6$ th of immediate sales responses to

\footnotetext{
${ }^{4}$ Principal components analysis also captures significant variation in variables and can be used to reduce dimensionality. However, the advantage of the lasso is that it specifically selects the aspects of weather that are most predictive for a specific contemporaneous, immediate outcome.

${ }^{5}$ I describe in Section 4.2 the set of interacted non-linear weather variables I feed into the lasso. Conceptually, they include terms as varied as temperature cubed in the summer in the Southeast, temperature times precipitation in the Northeast, and uninteracted linear snowfall.
} 
weather are offset through venue switching. Weather-induced gains and losses in stores do not appear to be offset by contemporaneous losses or gains on the firm's website. Instead, I find weather favorable for stores also drives up sales on the firm's website. Finally, immediate losses in store sales resulting from unfavorable weather shocks are persistent and not followed by meaningful offsetting gains in the weeks that follow. In contrast, the net effects on sales from positive weather shocks are not necessarily statistically significant by three weeks later, suggesting that the initial gains from favorable weather may be largely offset by losses in surrounding weeks. These findings and the results relating to long-run adaptation are robust to a series of alternative specifications as well as placebo tests in which I shuffle the weather by month or by location.

Taken together, my short- and long-run findings suggest responses to weather are complex with multiple mechanisms in play. The shift in sales from outdoor to indoor stores in response to precipitation and extreme heat could be explained by consumers being sensitive to the quality of shopping experiences. Two results are consistent with weather affecting sales through the ease of getting to stores: (1) significant snowfall decreases sales at both indoor and outdoor shopping centers and (2) locations with less experience with snow see larger sales declines in response to it. The finding that losses in stores are not made up in the following weeks or on the firm's website may signify that weather affects underlying demand for the durable goods sold by this brand. This could reflect a shift in activities for which consumers purchase products or changes in shoppers' inclinations to make impulse purchases. The result that a good portion of the initial gains from favorable weather are likely offset in surrounding weeks could be explained by pulling forward demand, which could result from stores responding to the weather by putting on special sales. Lack of adaptation to extreme heat could be explained by heat reducing underlying demand for the firm's products, some of which are likely used for outdoor activity.

The findings I present here have several important implications for firms and policymakers. First, weather's persistent and significant effects on sales imply weather 
shocks can affect firm profitability, volatility of sales, and worker wages in meaningful ways. As climate increases the frequency of more severe weather events, it may become increasingly important for firms to proactively adjust inventory, staffing, compensation, and financial reporting in response to weather shocks. ${ }^{6}$ Policymakers may need to directly address negative impacts of increasing income volatility for retail workers. Second, examining only immediate, contemporaneous responses to weather could overstate total weather effects, as some immediate effects appear to be offset across store types and time. Third, adaptation in retail sales should be accounted for when applying current weather responses to future climate projections. For this brand, lower sensitivity to precipitation, snow, and cold weather events in areas more experienced with them suggests that the long-run impacts of such events may be more moderate than in the absence of adaptation. However, in the short run, these types of events may be even more disruptive than average responses would imply if as locations increasingly face weather events that they are inexperienced with. Further, the surprising finding that more experience with extreme heat does not reduce sensitivity to such events suggests this firm may see increasingly large negative effects from heat as climate change progresses. It may need to shift the composition of its product lines. Finally, the finding that weather induces shifts in sales across stores suggest brands could benefit in the long run from diversifying the types of stores they operate.

To summarize, this paper makes several key contributions. First, the weather index is a novel method that can be applied in other settings to facilitate broader inquiry about dynamic responses to weather. Second, this paper builds on a significant literature examining weather effects on retail sales by applying the weather index to a unique, high-resolution data set that spans a broad range of climates to show that immediate short-run responses to weather are persistent even when accounting for partial offsetting from shifts of sales across store types, across time, and to the firm website. Third, the finding that sales sensitivity declines with historical experience

\footnotetext{
${ }^{6}$ In this spirit, recent literature in the field of operations management has suggested that firms adjust pricing and inventory in response to weather (see Belkaid and de Albéniz, 2021.)
} 
with precipitation, snow, and cold weather but not extreme heat contributes to both the literature on weather and sales and the broad literature examining adaptation in a variety of other settings.

The remainder of this paper is laid out as follows. In section 2, I provide a brief overview of relevant prior literature. In sections 3 and 4, I describe the data and empirical methodology, respectively. I then present results in section 5 along with implications for optimal firm strategies. I conclude in section 6 with a discussion of the implications of these findings as well as suggestions for future work.

\section{Literature}

This paper contributes to several key literatures, including those examining weather effects in retail spending, responses of outdoor activity to weather, and adaptation to climate change. I discuss each of these in turn below.

The weather index methodology I develop is a key novel contribution to a significant literature on weather effects on retail sales, which has established that responses to weather can be complicated and depend on context - an important motivation for the index. Work examining how weather affects retail sales dates back to at least Steele (1951). Largely oriented toward marketing and operations management, this literature has primarily relied on data available at either very small temporal or geographic ranges or at large aggregated scales. Maunder (1973) establishes sales responses to abnormal temperature and precipitation vary by season. Parsons (2001), Bahng and Kincade (2012), Bertrand, Brusset and Fortin (2015), Parnaudeau and Bertrand (2018), and Aladangady et al. (2016) also find that weather has significant effects on retail sales.

My finding that weather effects are persistent and not simply offset over time or through other channels contributes to an unresolved question in the literature regarding the persistence of weather effects on sales. For example, Starr-McCluer (2000) shows the negative effects of cold winter weather on aggregate national retail sales (in some categories) are offset in subsequent months, yielding no meaningful net quar- 
terly effects. Bloesch and Gourio (2015) find (non-motor vehicle) retail sales bounce back after severe winter weather, but not necessarily enough to offset the losses during the month with bad weather. In contrast, Addoum, Ng and Ortiz-Bobea (2020) find only energy sector sales respond meaningfully to temperature fluctuations when using annual data on firm establishment sales. ${ }^{7}$ They also examine adaptation of sales to heat by estimating whether responses to temperature differ when establishments have annual temperatures in the top versus bottom half of the distribution and find no significant difference.

My finding that precipitation and temperature shift sales between store types complements recent work by Belkaid and de Albéniz (2021), who show that daily sales for an apparel brand in four European countries increase in indoor stores and decrease in outdoor stores in response to precipitation. They further show this effect is primarily driven by decreased foot traffic and, conditional upon entering a store, individuals in outdoor stores are more likely to make purchases when it rains. My short-run results build on this work by applying the weather index to yield more generic results on three offsetting channels in one context: indoor/outdoor, in-store/online, and intertemporal.

The persistent response of sales to weather that I find could be explained by shifts in demand. One relevant strand of literature has shown that weather can have psychological impacts on purchases (see for example, Howarth and Hoffman, 1984, Levi and Galili, 2008, Conlin, O'Donoghue and Vogelsang, 2007, Busse et al., 2014, and Li et al., 2015) and mood more generally (see for example, Baylis, 2020.) To the extent that a significant share of purchases are made on impulse, this psychological channel could be a key mechanism through which weather yields persistent effects on sales.

Given that my data are for the sales of apparel and sporting goods - some of which are likely bought specifically for outdoor activities - my analysis also relates to the literature examining how weather affects outdoor activity. Smith (1993) shows beach use, swimming, and playing golf and tennis respond to temperature, with some nonlin-

\footnotetext{
${ }^{7}$ For quarterly analyses, they impute establishment sales patterns using national quarterly sales patterns and annual establishment level sales.
} 
earity. Graff Zivin and Neidell (2014) show high temperatures decrease time allocated to outdoor leisure, while Chan and Wichman (2020) find leisure cycling activity is very responsive to temperature and precipitation. Tucker and Gilliland (2007) review 37 studies on how weather and seasonality affect physical activity and find 73 percent of the articles examined report significant impacts. Relatedly, Barwick et al. (2019) find that the number of transactions at physical stores decreases with pollution in China, suggesting that external environmental conditions influence how much people go out more broadly. These findings support the idea that weather could be affecting demand for underlying goods for the brand I study and that the experience of shopping itself is important both by shifting sales between outdoor and indoor stores, and by redirecting individuals from (impulse) shopping toward other activities.

Finally, my paper contributes to a large and growing body of work that has examined adaptation to climate for a broad range of outcomes, including agriculture and fisheries (see for example Schlenker and Roberts, 2009, Kala, 2017, and Shrader, 2017), health (see for example Deschênes and Greenstone, 2011 and Barreca et al., 2015), labor (Behrer and Park, 2017), and income (Deryugina and Hsiang, 2017). In addition, there is also a significant literature examining adaptation in response to natural disasters (see Hsiang and Narita, 2012 and Bakkensen and Mendelsohn, 2016). Some of these studies use a similar approach to the one I undertake here in examining longrun adaptation by interacting weather shocks with historical norms (see for example, Hsiang and Narita, 2012, Barreca et al., 2015, and Behrer and Park, 2017). On the whole, this literature suggests that while people can adapt to different climates, this adaptation is partial, a finding that is consistent with my results.

\section{Data}

I use two main categories of data to examine how retail sales respond to weather shocks and how sensitivity to weather shifts with climate: (1) retail sales data from an apparel and sporting goods brand and (2) contemporaneous and historical weather 
data. I describe each of these data sources in turn below.

\subsection{Sales data}

I use proprietary daily store level sales data for over 100 U.S. locations of a wellknown apparel and sporting goods brand that sells its products at its stores and on its website. The data span April 2010 through December 2013. To examine how weather might shift sales between store types, I have identified each store as either outdoor, which consumers must enter and exit through the outside while exposed to weather, or indoor, which are located in enclosed shopping centers that allow consumers to move freely between stores without braving the elements. Outdoor locations include strip malls and metropolitan shopping districts, while indoor stores are generally in fully enclosed malls. ${ }^{8}$ I use data from sales made on the firm's website to assess the extent to which immediate effects of weather shocks in stores are offset by online sales. Because I have the dates when sales were fulfilled rather than when they were placed, and fulfillment did not regularly occur on weekends during this period, I aggregate these data at a weekly level, with the week starting on Tuesdays. ${ }^{9}$ Although the online sales data I have are at the zip code level based on delivery addresses, I aggregate them to the MSA level in order to match them with the store data.

\subsection{Weather data}

I use weather station data from NOAA, National Centers for Environmental Information (NCEI). I inverse-distance weight observations from the weather stations at airports and weather forecast offices located within 70 miles and 400 meters elevation

\footnotetext{
${ }^{8}$ In some MSAs, I have sales data for both indoor and outdoor store types. Based on Google map directions between stores, I find that among stores located in MSAs that include both indoor and outdoor stores, about a quarter of the stores are located within a 15-minute or 10-mile drive of the closest store of the "counterpart" type, about half within a 25-minute or 20-mile drive, and about three-quarters within a 30-minute or 30-mile drive. Thus, indoor and outdoor stores within the same MSA are generally close enough to make switching between store types a feasible option for consumers, allowing me to examine such shifts in response to weather shocks.

${ }^{9}$ It is my understanding from discussions with managers at the firm that during the period covered by my data, sales were typically fulfilled by the end of the first business day after the customer placed the purchase.
} 
of each store location to obtain store-level weather data. The weather elements I use include maximum temperature (TMAX), minimum temperature (TMIN), precipitation (PRCP), snowfall (SNOW), and snow depth (SNWD). ${ }^{10}$ I average over daily maximum and minimum temperatures to calculate daily average temperature (TAVG).

I exclude stations missing more than 5 percent of precipitation or temperature observations during my time frame. This yields up to seven weather stations per location and causes me to drop several stores due to insufficient observations. I use OLS regressions of weather station observations on other nearby weather station observations to impute remaining missing data. Finally, I replace missing snowfall and snow depth data with zeros when national monthly snowfall maps indicate there was no snow at the weather station locations in the applicable months.

To address potential climate-based heterogeneity in responses to weather events, I assign each store location to the corresponding climate region in the National Climate Assessment (Melillo, Richmond and Yohe, 2014.) With national representation, my data include a wide range of climates. For example, while Northwest locations have the highest share of days with positive precipitation, they are far less likely to experience daily precipitation over 2 inches than Southeast locations. My data include significant variation in observed temperature, snowfall, and snow depth distributions. ${ }^{11}$

I calculate historical normals and standard deviations of weather elements using weather observations from 1980-2009. For each calendar day $d$ (e.g., January 18), I apply a Bartlett weighting kernel over the historical observations for days $d-14, \ldots, d+14$ (e.g., January 4 - February 1) to calculate the daily historical normal and standard deviation for each element at each station. This kernel places the greatest weight on historical observations on day $d$, with the weights on the surrounding days $d \pm h$ diminishing linearly with $h$. Smoothing over 870 historical observations for each day $d$ reduces noise in daily historical normals and standard deviations from rare events like large rainfalls, avoiding large discrete jumps from one day to the next. This method

\footnotetext{
${ }^{10}$ Data on humidity or wind were completely unavailable or frequently missing.

${ }^{11}$ Figure A1 illustrates the wide variety of regional weather distributions.
} 
allows the mean temperature to gradually increase or decrease over the course of a month, avoiding discrete jumps at the start and end of each month that would result from calculating means and standard deviations by calendar month.

I further calculate the share of days over the entire historical period on which particular events occur (e.g., average temperature above $80 \mathrm{~F}$ or snowfall greater than 6 inches). For any given store, while the historical normal temperature shifts over the course of a year, this last set of variables indicating the share of historical observations exceeding a threshold does not vary over time. As the summary statistics in Appendix Table A2 show, the data include a wide range of historical normals and standard deviations as well as shares of historical observations exceeding various thresholds. ${ }^{12}$

\section{Empirical Strategy and Weather Index}

In this paper, I apply a range of empirical strategies, including the novel weather index. In this section, I start by describing the baseline specification, which includes the controls I use throughout. I then describe in greater detail the motivation for and construction of the weather index, which I use in Sections 5.1-5.3 to estimate dynamic short-run responses of sales to weather shocks. Finally, I discuss the approaches I use to estimate how sensitivity of sales to weather changes with historical experience, an important measure relating to adaptation to climate.

\subsection{Baseline model}

Although I model weather in a variety of ways to answer specific types of questions, the common theme in my empirical strategy is the inclusion of a set of fixed effects and controls that capture seasonal dynamics and trends in weather and sales. I use these to avoid, for example, attributing to cold weather any increases in sales that are due to December holiday shopping. In generic terms, the model I estimate for store $i$ and

\footnotetext{
${ }^{12}$ The historical normals and standard deviations align well with the means and standard deviations of contemporaneous weather observations in Appendix Table A1.
} 
day $t$ is:

$$
\ln \left(\text { Net Sales }_{i t}\right)=\boldsymbol{\omega} \cdot \text { weather }_{i t}+\alpha+\boldsymbol{\beta} \boldsymbol{X}_{i t}+\varepsilon_{i t},
$$

where

$$
\begin{aligned}
& \boldsymbol{X}_{i t} \equiv \boldsymbol{\alpha}_{t}+\boldsymbol{\alpha}_{i m}+\boldsymbol{\alpha}_{i w}+\boldsymbol{\beta}_{1 i} \cdot \text { store }_{i} \cdot t+\boldsymbol{\beta}_{2 i} \cdot \text { store }_{i} \cdot t^{2} \\
&+\boldsymbol{\beta}_{3} \cdot \text { store_closure_or_opening } \\
& i t
\end{aligned}
$$

The control vector $\boldsymbol{X}_{i t}$ includes the following controls. Date fixed effects $\left(\alpha_{t}\right)$ control for unobserved national and firm-wide events like promotions, releases of new products, or exogenous events like holidays that could be correlated with weather. Store-bycalendar month $\left(\alpha_{i m}\right)$ and store-by-day-of-week $\left(\alpha_{i w}\right)$ fixed effects control for storespecific seasonality, which could vary due to factors like tourism, school calendars, and climate. ${ }^{13}$ Store-specific linear and quadratic time trends capture location-specific trends, while indicators for the first or last week or month of a store's sales control for stores having different sales patterns early and late in their existence. ${ }^{14,15}$ I cluster standard errors by store and date.

\subsection{Weather index}

In equation (1), I have intentionally included weather in a generic form because I tailor the specification of weather to each application. The simplest way to model a weather element is in linear form, such as the average temperature on a day or the amount of precipitation or snowfall. Such a linear model is very tractable and lends itself to other analyses like adaptation to climate. I report results for such a model as a baseline in the adaptation section.

\footnotetext{
${ }^{13}$ See Online Appendix Figure B3.

${ }^{14} \mathrm{My}$ data include observations with 0 sales, which occur when stores are closed. These closures may result from very extreme weather events like Hurricane Sandy. To be conservative and maintain a focus on less extreme events, I exclude these observations because the $\ln (0)$ is undefined.

${ }^{15}$ Figure B2 shows the distribution of sales varies by month, day-of-week and holidays, which are controlled for by the date fixed effects, and by store openings and closures. Figure B3 shows that monthly and day-ofweek seasonality vary across stores, consistent with the inclusion of these components in the control vector.
} 
However, responses to weather are often nonlinear, an issue commonly addressed by binning element observations to non-parametrically estimate responses at various ranges. This popular method originated in agricultural analyses, where a biological mechanism underlies productivity responses. But in the context of retail sales, the physical link between particular temperature ranges and outcomes is less clear. What matters may be whether a given temperature is unusually warm or cold, which in turn depends on both location and time of year. Averaging responses to temperature ranges across time and space can make sales appear insensitive to temperature when there are large but heterogeneous responses. ${ }^{16}$

Another option is to model weather in terms of deviations from the mean (see for example Herrnstadt and Muehlegger (2014)). However, when compared to alternative activities, an unusually hot day in summer may make shopping-particularly in an air-conditioned indoor mall-relatively attractive, while an unusually warm winter day could make shopping relatively unattractive - again, particularly so in an indoor mall. Averaging across these heterogeneous responses to above- and below-mean weather could again make sales appear less sensitive to weather than they are.

Interactions between elements can further complicate matters. While, precipitation during warm weather can make shopping at an enclosed mall attractive, precipitation during extremely cold weather can make roads icy and preclude travel to any store. Non-parametric binning and deviations from means can miss these interactions and thus introduce bias when seeking to measure dynamics of responses to weather.

One might consider adding interaction terms to the above methods to allow for responses to weather to vary by context. ${ }^{17}$ However, doing so for all the potential dimensions - season, region, store type, weather element - could lead to overfitting and quickly makes it intractable to ask basic questions like: are contemporaneous responses

\footnotetext{
${ }^{16}$ For example, Figure A2 shows that, on average, sales respond to contemporaneous temperature in an inverted U-shape manner with the peak of that $\mathrm{U}$ being lower in winter than summer. Relative to days with average temperatures in the 70-75 degree range, a 45-60 degree range day appears to lower sales in summer but increase them in the winter. Averaging across seasons might suggest 45-60 degree days don't affect sales relative to $70-75$ degree days.

${ }^{17}$ Appendix Figure A2 illustrates this phenomenon by showing that temperature responses differ in summer and winter.
} 
to weather shocks simply offset in the days before or after the shocks?

I address the concerns outlined above by developing a weather index which measures how favorable weather conditions are for sales on a given day in each store. Separately developing weather indexes for indoor and outdoor stores, in the first step I regress sales and weather variables on control vector $\boldsymbol{X}_{i t}$ defined in equation (2) to generate residuals for each variable. The set of weather variables for which I do this is extensive and includes polynomials, interactions between elements, and interactions with indicators for seasons and regions, as outlined in Figure 1. Second, I use the lasso with 10fold cross-validation to select among these weather variable residuals those that are most predictive of residual sales. The cross-validation is designed to select a model that reduces out-of-sample prediction errors. Third, I estimate the model selected in the previous step but using the full sample. I use this estimate to then predict sales residuals. Finally, I standardize the predicted sales residuals to create a weather index $W_{i t}$ with a mean of 0 and a standard deviation of 1 across all stores and seasons. I standardize the indexes for indoor and outdoor stores separately. A high positive (negative) value indicates weather conditions are very (un)favorable for sales in the given store type, region, and season. In Sections 5.1-5.3, I use this index to examine the dynamics of short-run responses to weather, determining how weather shocks shift sales between store types, to the website, or over time. ${ }^{18}$

\subsection{Adaptation to climate}

I examine long-run adaptation to climate by assessing if sensitivity to weather events decreases with experience with those events, a proxy for climate adaptation investments that I am not able to observe directly. This approach is like that in Dell, Jones and Olken (2014) and is similar to a heterogeneity analysis in that I am examining how the

\footnotetext{
${ }^{18}$ To help develop intuition for the index, Figure A3 illustrates an example of how weather index values correspond to observed weather over the course of a year in a city in the Northeast. The upper panel shows indoor and outdoor weather index values, where positive (negative) values indicate that local current weather conditions are (un)favorable for sales. The shaded sections highlight periods during which the two indexes are negatively correlated, consistent with shifting of sales between store types. The lower panel shows precipitation in gray bars, snow depth in the thin solid line, snowfall as black dots, and maximum and minimum temperatures in the dashed and dash-dotted lines.
} 
causal impact of weather shocks varies by historical experience. Specifically, I estimate

$$
\ln \left(\text { Net Sales }_{i t}\right)=\alpha+\boldsymbol{\beta} \boldsymbol{X}_{i t}+\sum_{E \in \mathbb{E}}\left[\phi_{1} \cdot E_{i t}+\phi_{2} \cdot \mu_{i d}^{E} \cdot E_{i t}+\theta_{1} \cdot \mu_{i d}^{E}\right]+\varepsilon_{i t}
$$

where $E_{i t}$ is a weather element (like TMAX, PRCP, or SNOW), and $\mu_{i d}^{E}$ is the historical normal of the weather element on day of the year $d$ (e.g., May 4). Recall that $\mu_{i d}^{E}$ is based on the weather observed in the three decades before the start of the sample and thus does not vary from year to year within my sample but is specific to each calendar day $d$ (which can be inferred from date $t$ ) for each store. When $\phi_{1}$ and $\phi_{2}$ have opposite signs, the absolute effect of $E_{i t}$ on sales decreases as $\mu_{i d}^{E}$ increases. This means sensitivity of sales to a particular form of weather decreases with historical experience with that type of weather, a finding consistent with long-run adaptation.

In addition to examining historical normals, I build on the Dell, Jones and Olken (2014) specification in equation (3) by adding standard deviations to examine the relationship between weather sensitivity and more historical variability in weather. This is important because climate change projections suggest that some weather will become more extreme and variable, an increase in the standard deviation. I model this by adding the historical standard deviation interaction terms as follows:

$$
\begin{aligned}
\ln (\text { Net Sales } i t)= & \sum_{E \in \mathbb{E}}\left[\phi_{1} \cdot E_{i t}+\phi_{2} \cdot \mu_{i d}^{E} \cdot E_{i t}+\phi_{3} \cdot \sigma_{i d}^{E} \cdot E_{i t}+\theta_{1} \cdot \mu_{i d}^{E}+\theta_{2} \cdot \sigma_{i d}^{E}\right] \\
& +\alpha+\boldsymbol{\beta} \boldsymbol{X}_{i t}+\varepsilon_{i t} .
\end{aligned}
$$

As before, opposite signs on $\phi_{1}$ and $\phi_{3}$ are consistent with long-run adaptation.

Although the above method captures effects of anomalous weather when controlling for time of year, there is a potential that time-of-year specific historical normals and standard deviations may create false equivalences when two locations have the same historical normals or standard deviations at different times of the year. Consider two stores, A and B. Suppose store A is accustomed to large snowfall events from November through April. However, in October and May snowfall becomes unseasonable and historical normal snowfall is low. Suppose store B is in an area that rarely gets any 
significant snow and its peak normal snowfall in January is like the October normals for store B. Although for store A, a foot of snow may be more disruptive in October than in January, thanks to its physical and human capital it may still experience a smaller disruption in sales than store B would face with a foot of snow in January. A similar story could be told for extreme heat occurring at an unusual time of year in an area with hot summers and widespread air conditioning versus it occurring in the middle of summer in an area with historically mild summers and little air conditioning.

I address these concerns by examining how responses to extreme weather events vary based on the historical experience by estimating

$$
\begin{aligned}
\ln \left(\text { Net Sales }_{i t}\right)= & \sum_{E \in \mathbb{E}}\left[\phi_{1}^{E} \cdot \mathbb{I}\left[E_{i t} \geqslant E^{\tau}\right]+\phi_{2}^{E} \cdot \mathbb{I}\left[E_{i t} \geqslant E^{\tau}\right] \cdot P^{h i s t}\left[E_{i} \geqslant E^{\tau}\right]\right] \\
& +\alpha+\boldsymbol{\beta} \boldsymbol{X}_{i t}+\varepsilon_{i t},
\end{aligned}
$$

where $E^{\tau}$ is some threshold (e.g., 2 inches of precipitation) and $P^{h i s t}\left[E_{i} \geqslant E^{\tau}\right]$ is the share of historical (1980-2009) observations at store $i$ on which the threshold was exceeded regardless of the time of year. ${ }^{19,20}$ Again, opposing signs on $\phi_{1}^{E}$ and $\phi_{2}^{E}$ for any $E$ are consistent with adaptation.

\section{$5 \quad$ Results}

In this section, I present results examining the dynamics of how sales respond in the short run to weather shocks and how contemporaneous sensitivity to those shocks reduces with climate experience - as measured by historical normals, standard deviations, and experience with extreme events.

\footnotetext{
${ }^{19}$ To keep notation simple, equation (5) does not reflect that for cold weather the extreme event occurs when temperature falls below a threshold.

${ }^{20}$ I do not include the $P^{\text {hist }}\left[E_{i} \geqslant E^{\tau}\right]$ terms on their own here because they are constant for each store and thus collinear with the store fixed effects.
} 


\subsection{Shifting of sales between indoor and outdoor stores}

I now examine whether sales shift between indoor and outdoor stores. Looking only at MSAs that have both indoor and outdoor stores, I separately aggregate daily MSAlevel sales and weather for indoor and outdoor stores (reflected by $j$ ). Specifically, I average the weather index values over store type $j$ within MSA $m$ on date $t$, giving me $W_{\text {outdoor }, m t}$ and $W_{\text {indoor,mt }}$. I define the following "counterpart" weather index:

$$
W C_{j m t}=W_{\text {outdoor }, m t} \cdot \mathbb{1}[j \neq \text { outdoor }]+W_{\text {indoor }, m t} \cdot \mathbb{1}[j \neq \text { indoor }]
$$

For outdoor stores in MSA $m, W C_{j m t}$ is the average of the weather index values for the indoor stores in MSA $m$ on date $t$. Conversely, for indoor stores, it is the average of the weather index values for the outdoor stores. I use these indexes to estimate the following equation:

$$
\ln \left(\text { Net } \operatorname{Sales}_{j m t}\right)=\alpha+\boldsymbol{\beta} \boldsymbol{X}_{j m t}+\gamma_{1} \cdot W_{j m t}+\gamma_{2} \cdot W C_{j m t}+\varepsilon_{j m t}
$$

Net Sales $j m t$ is the aggregate sales at type $j$ stores within MSA $m$ on day $t . \boldsymbol{X}_{j m t}$ includes the non-weather fixed effects and controls from equation (2) at the MSA instead of store level along with a variable for the number of stores in the MSA at time $t$ to allow sales to shift with entry and exit of stores. A negative $\gamma_{2}$ coefficient would be consistent with gains and losses at one type of store being at least partially offset at its counterpart type of store. Such shifting of sales would reduce the net impact of weather shocks on sales for the retail brand in MSAs where it has both types of stores.

Table 1 shows results from estimating equation (7). Column 1 shows that weather, on average, induces some modest shifts in sales between indoor and outdoor stores. Suppose the indoor weather index in an MSA has a value of +1 (indicating a onestandard deviation magnitude favorable weather event for indoor stores.) This corre-

sponds to a 5.6 percent increase in contemporaneous sales at local indoor stores. If that same weather is a one-standard deviation negative weather shock for local out- 
door stores (i.e., the outdoor weather index is -1), sales at the indoor stores increase a further 0.9 percentage points. In other words, the counterpart weather index contains information for sales at a store type beyond what the basic weather index captures. ${ }^{21}$ Examining responses for indoor and outdoor stores separately in column 2, I find outdoor store sales are on average more sensitive to weather, as evidenced by the higher coefficient on Outdoor $\times W_{j m t}$ than on Indoor $\times W_{j m t}$. Furthermore, it appears outdoor store sales respond more to how favorable conditions are for indoor stores than vice versa. In column 3 , which examines potential seasonal heterogeneity, I find the coefficient on the counterpart index is largest in fall, but none of the season-specific counterpart weather index terms are statistically significant. Finally, column 4 shows there is regional heterogeneity in weather-induced shifting of sales between indoor and outdoor stores. This phenomenon offsets as much as half of the immediate sales effects in the Great Plains.

I dig deeper into shifting of sales between store types by next estimating responses of sales at indoor and outdoor stores to non-parametric bins of weather elements. Figure 2 shows responses of daily net sales to average temperature, precipitation, snowfall and snow depth at indoor and outdoor stores. Panel (a) shows results relative to days in the $70-75^{\circ} \mathrm{F}$ range, while the remaining panels show results relative to zero precipitation, snowfall, or snow depth. Panel (a) controls for precipitation, snowfall, and snow depth, while the remaining panels control for temperature.

Figure 2 panels (a), (c), and (d) suggest neither temperature nor snow consistently shifts sales between indoor and outdoor stores, as the coefficient estimates within bins are similar or have overlapping confidence intervals. In contrast, panel (b) shows precipitation results in offsetting sales patterns at indoor and outdoor stores. While any positive level of precipitation appears to on average drive down sales at outdoor stores, precipitation over $1 / 2$ inch appears to increase sales at indoor stores. However, not all coefficients in this range are statistically significant (which could be due to

\footnotetext{
${ }^{21}$ These findings are robust to the falsification tests shown in the (a) panels in Appendix Figures A5 and A6.
} 
heterogeneous effects or interactions with temperature, as discussed in section 4.2.)

In Table 2, I present results from regressions where the weather index for indoor stores is the dependent variable in columns 1 and 2, and the index for outdoor stores is the dependent variable in columns 3 and 4 . In columns 1 and 3 , I regress the weather indexes on a set of weather event indicators, and in columns 2 and 4, I interact those weather events with the counterpart weather index. The weather indicators equal one if it is hot with average temperature above $90^{\circ} \mathrm{F}$, it is freezing, or if there is positive precipitation, snowfall, or snow depth.

The Table 2 results again suggest precipitation induces shifts in sales from outdoor to indoor stores, as the coefficients on positive precipitation interacted with the counterpart weather index in columns 2 and 4 are negative and statistically significant. The opposing signs on precipitation in columns 1 and column 3 further support the hypothesis that precipitation shifts sales from outdoor to indoor stores. The Table 2 results also indicate extreme heat may shift sales from outdoor to indoor stores, as the coefficient on hot weather interacted with the counterpart (outdoor) weather index in column 2 indicates that hot weather that decreases sales at outdoor stores likely simultaneously drives up sales at indoor stores. ${ }^{22}$ In contrast, snow and cold weather appear to be bad for both indoor and outdoor stores.

To summarize, these results indicate sales sometimes shift between indoor and outdoor stores in response to weather. However, on average only a limited share of the immediate sales response to weather is offset by shifting of sales between store types. The shifting between store types appears to be primarily driven by precipitation and likely extreme heat events, which both shift sales from outdoor to indoor stores. Precipitation and extreme heat likely impact the experience of shopping itself, making enclosed and air-conditioned indoor environments relatively more pleasant to be in, suggesting the relative utility of shopping can play a role in sales. In contrast, the finding that snow and cold weather drive sales down at both indoor and outdoor stores

${ }^{22}$ Note that Table B3 in the online appendix shows no significant evidence that sales shift when heat events are measured based on average temperatures exceeding $80 \mathrm{~F}$. 
can be explained by snow making it difficult to get to stores in the first place.

What are some strategies firms can implement given weather sometimes shifts sales between indoor and outdoor stores? In the short run, a firm with both indoor and outdoor locations in an area can shift staffing and inventory to indoor stores when rain and extreme heat are forecast. In the long run, a firm in an area with significant rain and extreme heat events may deliberately locate its stores in both outdoor shopping centers and indoor malls. To examine whether this brand's locations are consistent with such a choice, I calculate each MSA's share of days with positive snowfall, positive precipitation, and extreme heat (where the average temperature is at least $90 \mathrm{~F}$ ). Consistent with diversifying store types in areas that experience a lot of precipitation and extreme heat events, I find the half of MSAs with the most shares of days with extreme heat or significant precipitation are 10 to 20 percentage points more likely to have both indoor and outdoor store types than the remaining MSAs.

\subsection{Sales shifting from physical stores to online}

I now examine if sales shift from stores to the brand's website in response to weather shocks. When faced with unfavorable weather for shopping in stores-particularly weather that makes it difficult to get to the store - consumers may respond by making purchases online. To explore this dynamic, I regress weekly MSA-level e-commerce sales on weekly counts of the number of days on which the in-store weather index values fall in particular ranges. I estimate this relationship separately for the indoor index, the outdoor index, and an average of the two (the "mean index"). Positive coefficients at low in-store index value ranges would indicate that weather that is unfavorable for shopping in stores increases sales on the brand's website, thereby reducing the net impact of weather shocks for the brand.

Figure 3 shows the corresponding regression results. A downward sloping relationship in Figure 3 would be consistent with sales shifting from physical stores to online, as unfavorable weather (the lower percentiles of the weather index range, which on the left-hand side of the chart) would increase online sales. I do not find that weather con- 
ditions which decrease sales in stores drive up sales on the firm's website or vice versa. Instead of a downward slope, Figure 3 displays a flat or somewhat upward sloping curve. It shows weather favorable for shopping in physical stores also increases sales online, while weather bad for shopping in physical stores does not have a significant average net effect on sales at the brand's website. ${ }^{23}$

Several mechanisms could explain weather simultaneously driving up sales at stores and the firm's website. First, weather could be shifting underlying demand because products are purchased for specific weather-sensitive activities or because shoppers' proclivities to make purchases are affected by weather (as suggested by the literature mentioned in section 2 that shows weather can impact sales through psychological impacts). Second, shopping activity in stores may directly drive online sales, as customers find products they want in stores but purchase particular colors or sizes online. Third, the firm may respond to weather conditions I have identified as favorable for store sales by implementing promotions in both stores and on its website. Fourth, some weather conditions that decrease store sales could also make it difficult to shop online. For example, snow storms which make it difficult for shoppers and staff to get to stores may also result in power outages that make it difficult to shop online. However, these mechanisms could be expected to sync up responses of online and store sales to weather more broadly, in which case there would also be significant declines in online sales when weather is bad for shopping in stores. The lack of a significant decline at low store weather index values could be explained by an offsetting boost to website sales resulting from some sales being shifted from stores to the website.

The lack of a boost in online sales in response to weather unfavorable for store sales suggests this firm was not made whole through online sales offsetting losses in stores. The firm could potentially reduce total sales volatility and losses by offering carefully timed online promotions to shoppers with addresses in locations where the weather index is low for both indoor and outdoor stores.

\footnotetext{
${ }^{23}$ Table B5 in the Online Appendix, which shows how online sales respond to the negative extreme weather events examined in section 5.5, provides further evidence that weather events which are on average bad for sales in stores do not on average increase online sales.
} 


\subsection{Intertemporal substitution}

I now examine if the contemporaneous effects of weather shocks are offset during the week before or the three weeks after these events. I do this by incorporating leads and lags of the weather index $W_{i t}$ into equation (1) as follows:

$$
\ln \left(\text { Net Sales }_{i t}\right)=\sum_{h=-7}^{21} \boldsymbol{\omega}_{h} \boldsymbol{W}_{i, t-h}+\alpha+\boldsymbol{\beta} \boldsymbol{X}_{i t}+\varepsilon_{i t}
$$

Recall that by construction the weather index has a mean of zero and standard deviation of 1 , with positive values indicating weather favorable for shopping. Negative coefficients on lags and leads are thus consistent with intertemporal substitution from the firm's perspective.

The panels in Figure 4 show results from two joint regressions estimating versions of equation (8). Panels (a) and (b) show results from the first joint regression, which interacts continuous weather index values with indicators for those index values being positive or negative. Panels (c)-(f) show results from a regression which includes leads and lags of indicators which equal one when weather index values fall within particular ranges. The left-hand panels show dynamic responses to positive weather shocks, while the right-hand panels show dynamic responses to negative weather shocks. I show cumulative effects starting seven days prior to a weather event to answer the question of whether contemporaneous effects are offset over time. ${ }^{24}$

Panel (a) suggests positive weather shocks yield persistent effects on sales. By three weeks after a positive weather shock, the net effect of a one-standard deviation positive shock is a boost to sales of about 5 percent of one day worth of sales at a store. However, comparing the point estimate for the positive shock at $t=21$ in Figure 4 panel (a) to the distributions based on placebo data presented in the (a) panels of Appendix Figures A5 and A6 suggests the statistical significance may be somewhat marginal. Furthermore, panels (c) and (e) show the net effects on sales resulting from positive weather shocks between 1 and 2 standard deviations or greater

\footnotetext{
${ }^{24}$ I show the corresponding non-cumulative daily effects in Appendix Figure A4.
} 
than 2 standard deviations in magnitude are at best marginally statistically significant by the end of three weeks after the shock. In addition, the daily responses to positive weather shocks show multiple significant negative days in each of the panels (a), (c) and (e) of Appendix Figure A4. Although the net effect three weeks after a positive shock is not a precisely estimated zero, I cannot rule out the possibility that positive weather shocks on average simply reflect intertemporal shifts of sales.

In contrast, the persistence of negative weather shocks appears to be highly statistically significant. I find significant large net effects after three weeks across panels (b), (d), and (f) of Figure 4. Furthermore, the coefficient estimate for $t=21$ in panel (b) robust to a variety of specifications in Online Appendix Table B1 and is well beyond the distributions of coefficient estimates based on placebo data shown in the (a) panels of Appendix Figures A5 and A6 .

In addition to being statistically significant, negative weather shocks appear to result in large net losses. By the end of three weeks following a one-standard deviation negative shock, a store has lost about 10 percent of a day's sales. This is roughly twice the magnitude of the point estimate for the positive shock in Figure 4 panel (a). Panel (d) shows the average net loss from a 1-2 standard deviation negative weather shock (the 2nd-4th percentiles, roughly) amounts to about 20 percent of a day's sales by three weeks post-shock. Finally, a store loses about 40 percent of a day's sales on average by the end of three weeks after a day when the weather index value falls below -2 (about the worst 2 percent of weather days).

In summary, these results indicate immediate sales responses to unfavorable weather shocks are, on average, persistent and large and there is no indication that initial losses are made up in subsequent weeks, though sales gains from favorable weather are followed by some payback and may reflect timing shifts. This latter finding could be explained by favorable weather conditions making shopping a relatively attractive activity or increasing the utility of acquiring products sooner rather than later. For example, a shopper who was already planning to buy new running shoes at some point might buy them sooner if their alternative activity got rained out or if they want to 
immediately use the shoes on a particularly nice day for running. In contrast, having already established that only a small share of immediate sales responses to weather are offset on average by contemporaneous responses at other store types or on the website, the finding that losses from unfavorable weather events are not offset by prior or subsequent boosts to sales could be explained by weather events affecting underlying demand for products.

\subsection{Potential Strategies for Firms Given Findings on Dynamics of Short-Run Responses to Weather}

Given that weather shocks have persistent and significant impacts on net sales when accounting for shifts of sales between store types, to the website, and over time, retail managers may benefit a great deal from using the weather index to adjust inventory, staffing, compensation, and reporting. In the short run, managers of chain stores can apply the weather index to weather forecasts to prioritize building up inventory in locations where weather conditions will be most favorable for sales. They can create product category-specific weather indexes to prioritize which types of products to restock. Managers can schedule shifts so that more retail staff are on hand when weather is more favorable, a strategy that could be particularly beneficial if in-store shopping experiences on days with favorable weather also drive online sales. Retailers may even find it worthwhile to pay premium or overtime pay to compensate staff to come in on days with particularly favorable weather conditions. On the other hand, retailers who use variable pay to compensate employees based on sales quantities could use the weather index to adjust commissions, making the pay more fair and likely less variable.

Finally, firms can use the weather index to report weather-adjusted sales growth to investors. A firm can accomplish this by first regressing actual daily store sales on weather index observations to estimate a weather index beta. It would then estimate counterfactual sales by subtracting the product of the beta and the observed weather index values from the actual daily store sales. Here the counterfactual is that the weather index always equals zero. Finally, the firm would aggregate these counterfac- 
tual daily store level sales to the national quarterly level to develop counterfactual sales growth. This counterfactual growth gives investors an estimate of what sales would have been had there not been significant weather shocks, a valuable signal of underlying demand and performance of the brand. In performing such an analysis on the sales and weather in my sample, I estimate the standard deviation of year-over-year growth in quarterly national store sales would have been about 12 percent lower for weather-adjusted sales than it was for actual sales.

\subsection{Adaptation to Climate}

Having established that weather shocks can yield large effects on store sales that are not simply offset across store types, online, or in subsequent weeks, I turn now to examining if the sensitivity of store sales to weather decreases with experience. Table 3 shows results from estimating equations (3) and (4). I present baseline estimates in columns 1 and 4 for reference. Consistent with adaptation to climate, in columns 2 and 5, I find the coefficients on the historical normal interaction terms have the opposite signs of the coefficients on the uninteracted weather elements, with most coefficients being statistically significant. Columns 3 and 6 show historical standard deviations also have explanatory power. More historical experience with larger variation in weather events - which includes more severe precipitation or snowfall - decreases sensitivity to those weather events, again consistent with adaptation to climate.

How should we interpret the magnitudes shown in Table 3 ? Consider precipitation. Conditional on being positive, the median amount of precipitation is 0.09 inches, while

the 5th and 95th percentiles of $\mu_{i d}^{P R C P}$ are 0.03 and 0.23 inches, respectively. ${ }^{25} \mathrm{Ap}-$ plying the column 1 coefficient for precipitation to the median precipitation amount suggests that 0.09 inches of rain decreases sales by about 0.16 percent. Applying the coefficients from column 2 suggests 0.09 inches of precipitation would decrease net sales at a 5 th percentile store-day by about 0.69 percent and at a 95 th percentile store-day by 0.14 percent. There are two key implications of these estimates. First, the response

\footnotetext{
${ }^{25}$ These values can be found in Appendix Tables A1 and A2.
} 
at the 5 th percentile observation is roughly five times as large as at the 95 th percentile observation, suggesting that adaptation may play a very large role in moderating impacts of weather. Second, the estimated average effect (0.16) is very similar to that at the 95th percentile observation (0.16) and would thus significantly understate the impact of rain at the 5th percentile store. This feature could reflect that responses to particular events tend to be estimated based largely on observations in areas that tend to experience those events more frequently. As climate change increases the frequency of events in areas less experienced with them, failure to account for adaptation could actually cause us to under-estimate impacts of weather events going forward if we apply average responses to areas inexperienced with weather events.

Although it yields some valuable insights, this back-of-the-envelope analysis does not reflect that locations with a great deal of experience with weather like snow or precipitation tend to have times in the year at the start and end of their typical snowy or rainy season with very low historical normal snowfall or precipitation levels. During these times their historical normals and standard deviations look like those of stores in areas that get only very little or rare snow or precipitation.

In Table 4, I present an alternative analysis that addresses this concern and allows me to separately examine heat from cold. I estimate responses to particular extreme events in columns 1 and 4 and then interact them in columns 2 and 5 with their historical probability at each store. Here the store-specific probability does not vary over the course of a year and is instead based on the entire history from 1980-2009. (This contrasts with the normals and standard deviations which are specific to the time of year.) In columns 3 and 6 , I instead interact the occurrence of the extreme weather events with indicators for whether the store-specific historical probabilities are in the top half of the sample of stores for each weather event type.

Consistent with the findings from Table 3, the results in Table 4 show sensitivity of sales to cold weather, snow, and precipitation events declines with historical experience. For example, column 3 shows the average reduction in sales when the maximum temperature is below freezing is 80 percent smaller for stores whose historical likelihood 
of experiencing such cold temperatures is in the top half than for stores in the bottom half.

Surprisingly, I find no significant evidence of adaptation to extreme heat. Although columns 1 and 4 of Table 4 show that heat decreases sales at stores, the coefficients on the interaction terms in the remaining columns are either insignificant or negative, the opposite of what we would expect to see with adaptation. This result is robust to alternative controls and clustering, examining extremes separately for indoor and outdoor stores, limiting the sample to stores that have experienced the extreme heat events in question, and splitting out the $80-90 \mathrm{~F}$ observations from the $90 \mathrm{~F}+$ observations in joint regressions. ${ }^{26}$ Furthermore, the placebo test results in panel (d) of Appendix Figures A5 and A6 show that the point estimates in Table 4, column 3 fall well within the range of coefficient estimates based on the placebo data. Lack of adaptation to heat could be explained by a decrease in demand for apparel and goods for outdoor activity when it is hot out, an explanation consistent with the literature described in section 2 which shows that outdoor activities are sensitive to weather.

Taken together, these findings suggest that although climate change will likely increase the frequency and severity of some of the currently most disruptive events for this brand's store sales, adaptation to climate may over time reduce the impact of events like severe precipitation and snowfall. However, the lack of evidence supporting the hypothesis that sales at stores in locations with more experience with extreme heat are also less sensitive to extreme heat events, suggests there may be limits to adaptation to rising temperatures. This is an important limitation in the face of climate change. Furthermore, a reduction in experience with snow and cold weather events could actually increase sensitivity of sales to these types of events over time, making them more disruptive when they do occur, even if they occur less often on average. $^{27}$

\footnotetext{
${ }^{26}$ See Online Appendix Tables B8, B9, B10, and B11, respectively.

${ }^{27}$ Consider, for example, how disruptive the extreme cold was in Texas in February 2020 due largely to the infrequency of this type of event there.
} 


\section{Conclusion}

I have shown, in the context of a national apparel and sporting good brand's sales of its products at its stores and website, that weather can have large and persistent effects on sales in the short run. I have also found that sensitivity of sales to cold temperature, snow, and precipitation decreases with historical experience. In contrast, I have not found that sensitivity of sales decreases with historic experience with extreme heat events - which yield significant declines in sales. Firms like this one can expect climate change to increasingly yield extreme weather days that disrupt sales and operations, events that would currently register with large negative weather index values. These sorts of shocks may be particularly harmful to owners and staff of individual small businesses unable to diversify exposure to weather across a broad set of locations.

Under climate change it will become increasingly important for firms to proactively implement strategies that directly address weather effects. Firms using the weather index will have to periodically re-estimate it to account for shifting climates and adaptation. As discussed at the ends of Sections 5.1-5.2 and in Section 5.4, actions firms can take in the short run include shifting inventory and staffing in anticipation of weather shocks, adjusting compensation and reporting of sales results to reflect the role of weather, and implementing local online promotions when weather is unfavorable for nearby stores. Long-run strategies include diversifying the types of stores in areas with frequent significant precipitation and extreme heat. Firms could also perform analyses like those in this paper but on specific product categories - an analysis I am unable to perform due to lack of data on sales by product category - to inform which types of products to develop in the long run to reduce sensitivity of sales to weather shocks under climate change.

Regarding policy, my results suggest simply applying current contemporaneous responses to weather to simulated weather from climate change models without accounting for adaptation would likely overstate climate change impacts on sales in the long run. However, it would also be incorrect to assume perfect adaptation, as I find no 
evidence that sensitivity of sales to extreme heat declines with experience. As climate change drives up variability of weather, it will become increasingly important for policymakers to account for the role of weather in economic indicators like retail sales.

My findings also suggest individuals working in retail with sales-based pay or hourly wages may experience increasingly large income swings as weather becomes more variable and affects sales and hours worked. This type of volatility for relatively low-skilled laborers could present significant hardships, particularly if they are credit constrained and already struggling to smooth consumption (see for example Board of Governors of the Federal Reserve System (2019).) Given that retail trade employment accounted for roughly ten percent of total nonfarm employment in the United States in $2019,{ }^{28}$ increased weather-induced variability in sales is a potentially important channel through which climate change could impact inequality.

Future work could build on the findings in this paper by applying the weather index method to new data sets to gain deeper insights on short-run dynamics of responses to weather. For example, sales of categories of apparel and sporting goods that are useful in certain weather conditions like snow could increase in response to such weather even when net sales decrease at the store level. Applying the methods in this paper to specific product categories (for which I do not have data) could show more clearly what mechanisms drive sales responses. Analyses of individual or household level purchases or time spent shopping could shed more light on the mechanisms driving the findings in this paper. While the context in which I examine weather responsessales at an apparel and sporting goods brand-likely reflects a combination of weather impacts on sporting activities and on shopping more broadly, applying the methods in this paper to similarly granular and broad high frequency data on net sales of other types of retailers could shed light on the generalizability of my findings on short-run dynamics. An analysis of how retail worker earnings respond to weather could also have implications for policy under climate change, which may pose hardships by increasing

\footnotetext{
${ }^{28}$ Bureau of Labor Statistic "Employment by Industry" table, accessed on December 23, 2021 at https: //www.bls.gov/charts/employment-situation/employment-levels-by-industry.htm.
} 
the volatility of low-wage worker earnings.

Finally, it would be helpful to understand how generalizable my findings relating to climate adaptation are within the retail sector, particular the absence of evidence consistent with adaptation to extreme heat. The fact that Addoum, Ng and OrtizBobea (2020) also find no evidence consistent with adaptation of sales to heat suggests that this result could apply more broadly. However, given the annual frequency of their sales data, their lack of a finding on adaptation to extreme heat may be due to the low frequency of their outcomes. Future research that examines granular high frequency data that span a broad range of climates but apply to other types of retailers could prove insightful. In particular, it would be useful to know if other retailers see sensitivity of sales to extreme heat decrease with historical experience or if the lack of evidence consistent with adaptation to heat is a broader finding for retail sales. 


\section{References}

Addoum, Jawad M., David T. Ng, and Ariel Ortiz-Bobea. 2020. "Temperature Shocks and Establishment Sales." The Review of Financial Studies, 33(3): 13311366.

Aladangady, Aditya, Shifrah Aron-Dine, Wendy Dunn, Laura Feiveson, Paul Lengermann, and Claudia Sahm. 2016. "The Effect of Hurricane Matthew on Consumer Spending." FEDS Notes. Washington: Board of Governors of the Federal Reserve System.

Bahng, Youngjin, and Doris H. Kincade. 2012. "The relationship between temperature and sales: Sales data analysis of a retailer of branded women's business wear." International Journal of Retail \& Distribution Management, 40(6): 410-426.

Bakkensen, Laura A., and Robert O. Mendelsohn. 2016. "Risk and Adaptation: Evidence from Global Hurricane Damages and Fatalities." Journal of the Association of Environmental and Resource Economists, 3(3): 555-587.

Barreca, Alan, Karen Clay, Olivier Deschênes, Michael Greenstone, and Joseph S. Shapiro. 2015. "Convergence in Adaptation to Climate Change: Evidence from High Temperatures and Mortality, 1900-2004." The American Economic Review: Papers 8 Proceedings, 105(5): 247-251.

Barwick, Panle Jia, Shanjun Li, Liguo Lin, and Eric Zou. 2019. "From fog to smog: The value of pollution information."

Baylis, Patrick. 2020. "Temperature and Temperament: Evidence from Twitter." Journal of Public Economics, 184: 104161.

Behrer, A. Patrick, and Jisung Park. 2017. "Will We Adapt? Temperature, Labor and Adaptation to Climate Change." Working Paper. 
Belkaid, Abdel, and Victor Martínez de Albéniz. 2021. "Here Comes the Sun: Fashion Goods Retailing under Weather Shocks." 3.

Bertrand, Jean-Louis, Xavier Brusset, and Maxime Fortin. 2015. "Assessing and hedging the cost of unseasonal weather: Case of the apparel sector." European Journal of Operational Research, 244(1): 261-276.

Bloesch, Justin, and François Gourio. 2015. "The effect of winter weather on US economic activity." Economic Perspectives, 39(1).

Board of Governors of the Federal Reserve System. 2019. "Report on the Economic Well-Being of U.S. Households in 2018." https: //www. federalreserve. gov/consumerscommunities/files/ 2018-report-economic-well-being-us-households-201905. pdf, Accessed: 2019-06-05.

Busse, Meghan R., Devin G. Pope, Jaren C. Pope, and Jorge Silva-Risso. 2014. "The Psychological effect of weather on car purchases." Quarterly Journal of Economics, 130(1): 371-414.

Chan, Nathan W, and Casey J Wichman. 2020. "Climate Change and Recreation: Evidence from North American Cycling." Environmental and Resource Economics, $1-33$.

Conlin, Michael, Ted O'Donoghue, and Timothy J. Vogelsang. 2007. "Projection Bias in Catalog Orders." American Economic Review, 97(4): 1217-1249.

Dell, Melissa, Benjamin F. Jones, and Benjamin A. Olken. 2014. "What do we learn from the weather? The new climate-economy literature." Journal of Economic Literature, 52(3): 740-798.

Deryugina, Tatyana, and Solomon Hsiang. 2017. "The Marginal Product of Climate." National Bureau of Economic Research Working Paper. 
Deschênes, Olivier, and Michael Greenstone. 2011. "Climate Change, Mortality, and Adaptation: Evidence from Annual Fluctuations in Weather in the US." American Economic Journal: Applied Economics, 3(4): 152-85.

Graff Zivin, Joshua, and Matthew Neidell. 2014. "Temperature and the Allocation of Time: Implications for Climate Change." Journal of Labor Economics, $32(1): 1-26$.

Hayhoe, K, DJ Wuebbles, DR Easterling, DW Fahey, S Doherty, J Kossin, W Sweet, R Vose, and M Wehner. 2018. "Our changing climate." Impacts, risks, and adaptation in the United States: fourth national climate assessment, 2: 72-144.

Herrnstadt, Evan, and Erich Muehlegger. 2014. "Weather, salience of climate change and congressional voting." Journal of Environmental Economics and Management, 68(3): 435-448.

Howarth, Edgar, and Michael S. Hoffman. 1984. "A multidimensional approach to the relationship between mood and weather." British Journal of Psychology, 75(1): 15-23.

Hsiang, Solomon M., and Daiju Narita. 2012. "Adaptation to Cyclone Risk: Evidence from the Global Cross-Section." Climate Change Economics, 3(2).

Kala, Namrata. 2017. "Learning, Adaptation, and Climate Uncertainty: Evidence from Indian Agriculture." Working Paper.

Levi, Ori, and Itai Galili. 2008. "Stock purchase and the weather: Individual differences." Journal of Economic Behavior and Organization, 67(3): 755-767.

Li, Chenxi, Andy Reinaker, Cheng Zhang, and Xueming Luo. 2015. "Weather and Mobile Purchases: 10-Million-User Field Study." Working Paper.

Maunder, W. J. 1973. "Weekly weather and economic activities on a national scale: An example using United States retail trade data." New Zealand Meteorological Service, 28(1): 2-19. 
Melillo, Jerry M., Terese (T.C.) Richmond, and Gary W. Yohe, ed. 2014. Climate Change Impacts in the United States: The Third National Climate Assessment. U.S. Global Change Research Program.

NOAA, National Centers for Environmental Information (NCEI) formerly known as National Climatic Data Center (NCDC). n.d.. "Global Historical Climatology Network Daily." https://www. ncdc. noaa. gov/ ghcnd-data-access, Accessed: 2015-04-22.

Parnaudeau, Miia, and Jean-Louis Bertrand. 2018. "The Contribution of Weather Variability to Economic Sectors." Applied Economics, 50(43): 4632-4649.

Parsons, Andrew G. 2001. "The Association between daily weather and daily shopping patterns." Australasian Marketing Journal, 9(2): 78-84.

Schlenker, Wolfram, and Michael J Roberts. 2009. "Nonlinear temperature effects indicate severe damages to US crop yields under climate change." Proceedings of the National Academy of sciences, 106(37): 15594-15598.

Shrader, Jeffrey. 2017. "Expectations and adaptation to environmental risks." Working Paper.

Smith, Keith. 1993. "The influence of weather and climate on recreation and tourism." Weather, 48(12): 398-404.

Starr-McCluer, Martha. 2000. "The Effects of Weather on Retail Sales." Divisions of Research 85 Statistics and Monetary Affairs, Federal Reserve Board.

Steele, A.T. 1951. "Weather's effect on the sales of a department store." Journal of Marketing, 15(4): 436-443.

Tucker, Patricia, and Jason Gilliland. 2007. "The effect of season and weather on physical activity: a systematic review." Public health, 121(12): 909-922. 


\section{Tables and Figures}

Table 1: Shifting of sales between indoor and outdoor stores

\begin{tabular}{lr}
\hline Dep var: $\ln ($ Net Sales $)$ & $(1)$ \\
\hline Weather index & $0.056^{* * *}$ \\
Counterpart weather index & $-0.009^{* * *}$
\end{tabular}

Indoor vs. outdoor stores

\begin{tabular}{lc} 
Indoor $\times W_{j m t}$ & $0.041^{* * *}$ \\
Indoor $\times W C_{j m t}$ & -0.001 \\
\hline Outdoor $\times W_{j m t}$ & $0.078^{* * *}$ \\
Outdoor $\times W C_{j m t}$ & $-0.018^{* * *}$
\end{tabular}

\section{Seasons}

\begin{tabular}{lc} 
Spring $\times W_{j m t}$ & $0.061^{* * *}$ \\
Spring $\times W C_{j m t}$ & -0.006 \\
\hline Summer $\times W_{j m t}$ & $0.056^{* * *}$ \\
Summer $\times W C_{j m t}$ & -0.001 \\
Fall $\times W_{j m t}$ & $0.069^{* * *}$ \\
Fall $\times W C_{j m t}$ & -0.020 \\
Winter $\times W_{j m t}$ & $0.050^{* * *}$ \\
Winter $\times W C_{j m t}$ & -0.006
\end{tabular}

\section{Regions}

\begin{tabular}{|c|c|c|c|c|}
\hline \multirow{2}{*}{\multicolumn{4}{|c|}{$\begin{array}{l}\text { Great Plains } \times W_{j m t} \\
\text { Great Plains } \times W C_{j m t}\end{array}$}} & $0.043^{* * *}$ \\
\hline & & & & $-0.023^{* * *}$ \\
\hline \multirow{2}{*}{\multicolumn{4}{|c|}{$\begin{array}{l}\text { Midwest } \times W_{j m t} \\
\text { Midwest } \times W C_{j m t}\end{array}$}} & $0.058 * * *$ \\
\hline & & & & $-0.005^{* *}$ \\
\hline \multicolumn{4}{|l|}{ Northeast $\times W_{j m t}$} & $0.054^{* * *}$ \\
\hline \multicolumn{4}{|l|}{ Northeast $\times W C_{j m t}$} & $-0.011^{* * *}$ \\
\hline \multicolumn{4}{|l|}{ Northwest $\times W_{j m t}$} & $0.078^{* * *}$ \\
\hline \multicolumn{4}{|l|}{ Northwest $\times W C_{j m t}$} & $-0.015^{* * *}$ \\
\hline \multicolumn{4}{|l|}{ Southeast $\times W_{j m t}$} & $0.056 * * *$ \\
\hline \multicolumn{4}{|l|}{ Southeast $\times W C_{j m t}$} & -0.003 \\
\hline \multicolumn{4}{|l|}{ Southwest $\times W_{j m t}$} & $0.047 * * *$ \\
\hline \multicolumn{4}{|l|}{ Southwest $\times W C_{j m t}$} & -0.014 \\
\hline Observations & 32,036 & 32,036 & 32,036 & 32,036 \\
\hline Adjusted $\mathrm{R}^{2}$ & 0.958 & 0.958 & 0.958 & 0.958 \\
\hline
\end{tabular}

Note: This table shows results from regressing the log of aggregate net sales at all stores of type $j$ (indoor or outdoor) in MSA $m$ on day $t$ on the "weather index" for that store type $\left(W_{j m t}\right)$ as well as the weather index for the counterpart store type $\left(W C_{j m t}\right)$. With a mean of 0 and standard deviation of 1 , the weather index measures how favorable weather conditions are for sales. A more positive value corresponds to a more positive weather shock. Constructed using the lasso machine learning method with cross-validation in a residuals-on-residuals framework to select among thousands of potential interacted and non-linear weather variables, the index flexibly reflects the contemporaneous weather shock for a specific store on a specific day. For observations of sales at indoor stores, the "counterpart" weather index refers to the weather index for outdoor stores, and vice versa. "Indoor" stores are in shopping centers where patrons can move between stores without being exposed to weather. Regressions control for date, MSA-weekday, and MSA-month fixed effects, MSA-specific trends and number of stores. ${ }^{*} p<0.10$, ${ }^{* *}$ $p<0.05,{ }^{* * *} p<0.01$

Source: proprietary sales data; NOAA, National Centers for Environmental Information (NCEI). Global Historical Climatology Network Daily. (Accessed April 22, 2015.) 
Table 2: Relationship between indoor and outdoor weather indexes

Dep var: Weather index

(1)

Avg temp $>90 \mathrm{~F}$

Max temp $<0 \mathrm{C}$

Positive precipitation

Positive snowfall

Positive snow depth

Counterpart weather index

Counterpart weather index $\times$ Avg temp $>90 \mathrm{~F}$

Counterpart weather index $\times$ Max temp $<0 \mathrm{C}$

Counterpart weather index $\times$ Positive precipitation

Counterpart weather index $\times$ Positive snowfall

Counterpart weather index $\times$ Positive snow depth
Indoor Stores

(2)

(3)

Outdoor Stores

\begin{tabular}{lcccc} 
& 0.025 & & $-0.556^{* * *}$ & \\
& -0.573 & & $-0.960^{* * *}$ & \\
& $0.342^{* * *}$ & & -0.110 & \\
& $-1.226^{* *}$ & & $-1.854^{* * *}$ & \\
& $-1.196^{* * *}$ & & $-1.159^{* * *}$ & \\
& & $0.839^{* * *}$ & & $0.392^{* * *}$ \\
OF & & $-0.476^{* *}$ & & 0.077 \\
C & & -0.230 & & $0.486^{* * *}$ \\
altation & & $-0.652^{* * *}$ & & $-0.294^{* * *}$ \\
depth & & $0.424^{*}$ & & $0.708^{* * *}$ \\
& 16,016 & $0.312^{* *}$ & -0.034 \\
\hline & 0.133 & 0.369 & 0.270 & 0.485 \\
\hline
\end{tabular}

Observations

Adjusted $\mathrm{R}^{2}$

Note: This table shows results from regressing the average MSA $m$ "weather index" for store type $j$ (indoor or outdoor) on a set of indicators for weather events, which in columns (2) and (4) are interacted with the weather index for the counterpart store type. With a mean of 0 and standard deviation of 1 , the weather index measures how favorable weather conditions are for sales. A more positive value corresponds to a more positive weather shock. Constructed using the lasso machine learning method with cross-validation in a residuals-on-residuals framework to select among thousands of potential interacted and non-linear weather variables, the index flexibly reflects the contemporaneous weather shock for a specific store on a specific day. "Indoor" stores are in shopping centers where patrons can move between stores without being exposed to weather. For observations of sales at indoor stores, the "counterpart" weather index refers to the weather index for outdoor stores, and vice versa. Regressions include only MSAs with indoor and outdoor stores and control for date, MSA-weekday, and MSA-month fixed effects as well as MSA-specific trends and number of stores. $* p<0.10, * *$ $p<0.05, * * * p<0.01$

Source: proprietary sales data; NOAA, National Centers for Environmental Information (NCEI). Global Historical Climatology Network Daily. (Accessed April 22, 2015.) 
Table 3: Adaptation to weather normals and standard deviations

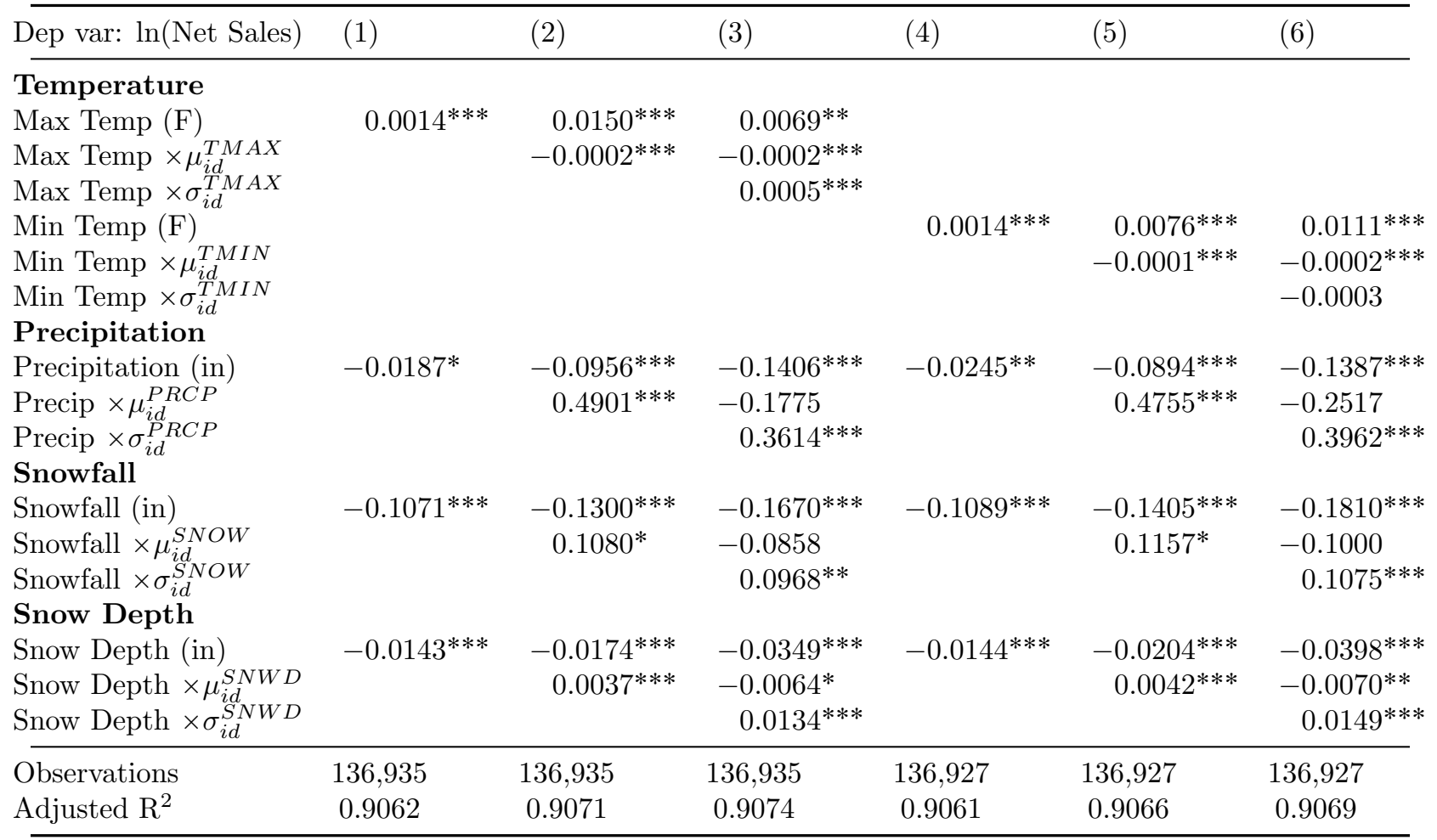

Note: This table shows results from regressing log of daily store level sales on weather and interactions between contemporaneous weather observations and their historical normals $\left(\mu_{i d}^{E}\right)$ and standard deviations $\left(\sigma_{i d}^{E}\right)$. The historical normals and standard deviations are calculated for each calendar day $d$ using Bartlett kernel weights to smooth over historical observations from 1980-2009. All columns control for date, store-month, and store-day-of-week fixed effects as well as store-specific trends and indicators for store openings and closings. Columns 2 and 5 also include the uninteracted historical normals as controls while columns 3 and 6 include the uninteracted historical normals and standard deviations as controls. Robust standard errors are clustered by MSA and by date. ${ }^{*} p<0.10,{ }^{* *} p<0.05, * * * p<0.01$

Source: proprietary sales data; NOAA, National Centers for Environmental Information (NCEI). Global Historical Climatology Network Daily. (Accessed April 22, 2015.) 
Table 4: Adaptation to discrete extreme weather events based on historical experience with those events

\begin{tabular}{|c|c|c|c|c|c|c|}
\hline Dep var: $\ln$ (Net Sales) & (1) & $(2)$ & $(3)$ & $(4)$ & $(5)$ & $(6)$ \\
\hline \multicolumn{7}{|l|}{ Extreme heat } \\
\hline $\mathrm{TAVG} \geqslant 80 \mathrm{~F}$ & $-0.020^{* * *}$ & -0.000 & -0.009 & & & \\
\hline$($ TAVG $\geqslant 80 \mathrm{~F}) \times($ share $\geqslant 80 \mathrm{~F})$ & & $-0.119^{*}$ & & & & \\
\hline$($ TAVG $\geqslant 80 F) \times($ top half $)$ & & & -0.015 & & & \\
\hline TAVG $\geqslant 90 \mathrm{~F}$ & & & & $-0.043^{* * *}$ & $-0.040^{* *}$ & -0.072 \\
\hline$($ TAVG $\geqslant 90 \mathrm{~F}) \times($ share $\geqslant 90 \mathrm{~F})$ & & & & & -0.036 & \\
\hline$($ TAVG $\geqslant 90 \mathrm{~F}) \times($ top half $)$ & & & & & & 0.029 \\
\hline \multicolumn{7}{|l|}{ Extreme Cold } \\
\hline $\mathrm{TMAX} \leqslant 0 \mathrm{C}$ & $-0.087^{* * *}$ & $-0.181^{* * *}$ & $-0.409^{* * *}$ & & & \\
\hline$($ TMAX $\leqslant 0 \mathrm{C}) \times($ share $\leqslant 0 \mathrm{C})$ & & $0.895^{* * *}$ & & & & \\
\hline$(\mathrm{TMAX} \leqslant 0 \mathrm{C}) \times($ top half $)$ & & & $0.328^{* *}$ & & & \\
\hline $\mathrm{TAVG} \leqslant 15 \mathrm{~F}$ & & & & $-0.078^{* * *}$ & $-0.143^{* * *}$ & $0.153^{* * *}$ \\
\hline$($ TAVG $\leqslant 15 \mathrm{~F}) \times($ share $\leqslant 15 \mathrm{~F})$ & & & & & $1.148^{*}$ & \\
\hline$(\mathrm{TAVG} \leqslant 15 \mathrm{~F}) \times($ top half $)$ & & & & & & $-0.207^{* * *}$ \\
\hline \multicolumn{7}{|l|}{ Precipitation } \\
\hline $\begin{array}{l}\mathrm{PRCP} \geqslant 1 \text { in } \\
(\mathrm{PRCP} \geqslant 1 \text { in }) \times(\text { share } \geqslant 1 \text { in })\end{array}$ & $-0.039^{* *}$ & $\begin{array}{r}-0.153^{* * *} \\
3.626^{* * *}\end{array}$ & $-0.063^{* * *}$ & & & \\
\hline$(\mathrm{PRCP} \geqslant 1$ in $) \times($ top half $)$ & & & 0.034 & & & \\
\hline $\begin{array}{l}\mathrm{PRCP} \geqslant 2 \text { in } \\
(\mathrm{PRCP} \geq 2 \text { in }) \times(\text { share } \geq 2 \text { in })\end{array}$ & & & & $-0.061^{*}$ & $\begin{array}{r}-0.193^{* * *} \\
17275^{* * *}\end{array}$ & $-0.142^{* * *}$ \\
\hline$(\mathrm{PRCP} \geqslant 2$ in $) \times($ top half $)$ & & & & & & $0.116^{* *}$ \\
\hline \multicolumn{7}{|l|}{ Snowfall } \\
\hline $\begin{array}{l}\text { SNOW } \geqslant 1 \text { in } \\
(\text { SNOW } \geqslant 1 \text { in }) \times(\text { share } \geqslant 1 \text { in })\end{array}$ & $-0.350^{* * *}$ & $\begin{array}{r}-0.482^{* * *} \\
4.588^{* * *}\end{array}$ & $-0.379^{* * *}$ & & & \\
\hline$(\mathrm{SNOW} \geqslant 1$ in $) \times($ top half $)$ & & & 0.029 & & & \\
\hline $\begin{array}{l}\text { SNOW } \geqslant 6 \text { in } \\
(\text { SNOW } \geqslant 6 \text { in }) \times(\text { share } \geqslant 6 \text { in })\end{array}$ & & & & $-0.722^{* * *}$ & $\begin{array}{r}-0.946^{* * *} \\
71.629^{* * *}\end{array}$ & $-1.220^{* * *}$ \\
\hline$(\mathrm{SNOW} \geqslant 6$ in $) \times($ top half $)$ & & & & & & $0.520 * * *$ \\
\hline \multicolumn{7}{|l|}{ Snow Depth } \\
\hline $\begin{array}{l}\mathrm{SNWD} \geqslant 1 \text { in } \\
(\mathrm{SNWD} \geqslant 1 \text { in }) \times(\text { share } \geqslant 1 \text { in })\end{array}$ & $-0.081^{* * *}$ & $\begin{array}{l}-0.107^{* * *} \\
0.264\end{array}$ & $-0.335^{* * *}$ & & & $-0.403^{* * *}$ \\
\hline$(\mathrm{SNWD} \geqslant 1$ in $) \times($ top half $)$ & & & $0.256^{* * *}$ & & & $0.272^{* * *}$ \\
\hline $\mathrm{SNWD} \geqslant 6$ in & & & & $-0.109^{* * *}$ & $-0.191^{* * *}$ & \\
\hline$(\mathrm{SNWD} \geqslant 6$ in $) \times($ share $\geqslant 6$ in $)$ & & & & & $1.975^{* *}$ & \\
\hline Observations & 136,846 & 136,846 & 136,846 & 136,846 & 136,846 & 136,846 \\
\hline Adjusted $\mathrm{R}^{2}$ & 0.906 & 0.906 & 0.906 & 0.905 & 0.905 & 0.905 \\
\hline
\end{tabular}

Note: This table shows results from regressing log of daily store level sales on indicators for weather events and interactions between those indicators and measures of the historical frequency of those events (columns 2 and 5) or indicators for whether the historical frequency of those events is above the median historical frequency (columns 3 and 6). Based on observations from 1980-2009, the share of historical observations on which a weather event occurs remains fixed over time for any given store. All columns control for date, store-month, and store-day-of-week fixed effects as well as store-specific trends and indicators for store openings and closings. Robust standard errors are clustered by MSA and by date. ${ }^{*} p<0.10,{ }^{* *} p<0.05,{ }^{* * *} p<0.01$

Source: proprietary sales data; NOAA, National Centers for Environmental Information (NCEI). Global Historical Climatology Network Daily. (Accessed April 22, 2015.) 
Figure 1: Inputs to Lasso for Weather Index Construction

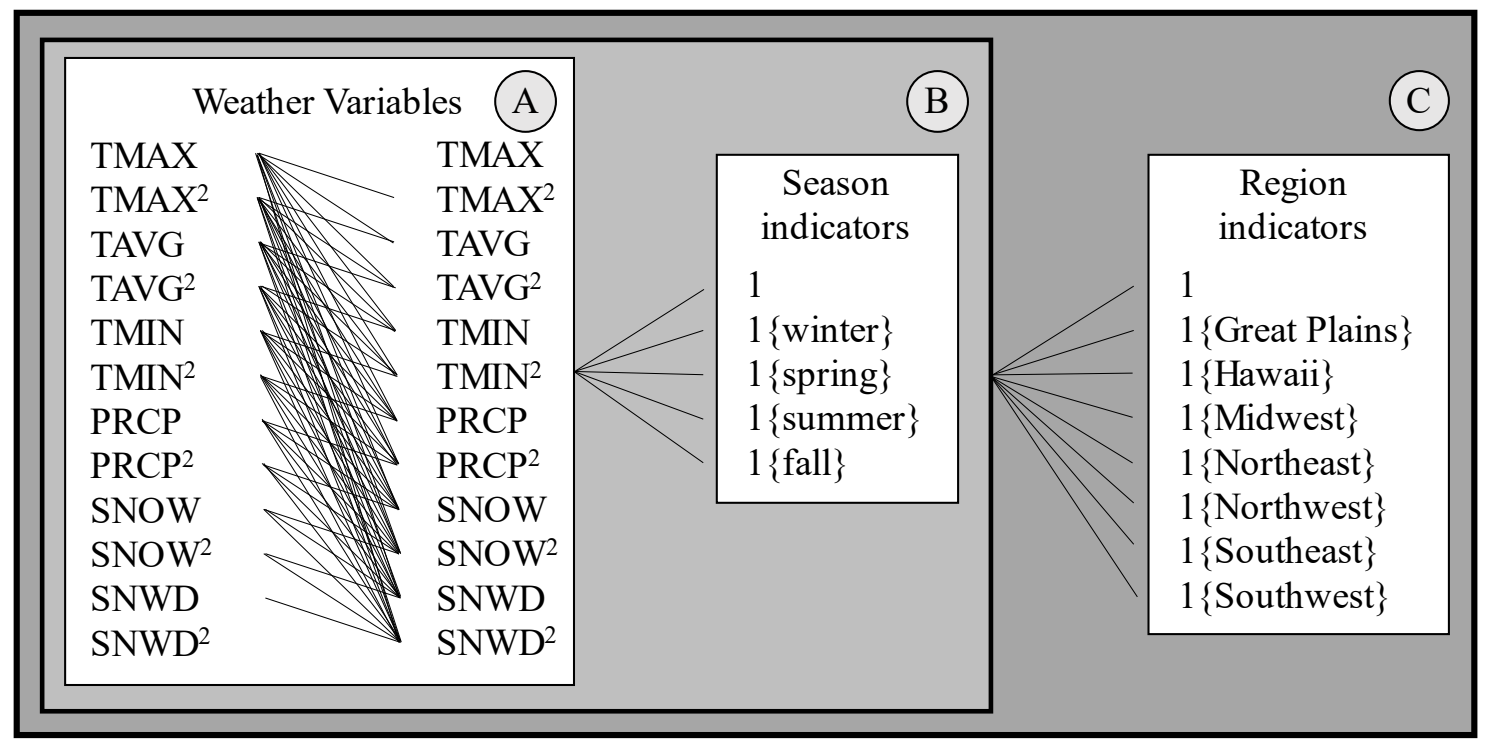

Note: This schematic depicts the variables whose residuals are included in the lasso to create the weather index.

The left column of Panel (A) shows the weather variables that are interacted with each other. TMAX, TAVG, and TMIN refer to the maximum, average, and minimum temperatures, respectively, PRCP refers to precipitation, SNOW refers to snowfall, and SNWD refers to snow depth. Each of the variables in the left column is included on its own and is interacted with each of the other variables, as indicated by the lines connecting the two columns in panel (A). For example, TMAX, TMAX ${ }^{2}$, TMAX $^{3}$ (a product of TMAX and TMAX $^{2}$ ), TMAX·TAVG, TMAX·PRCP ${ }^{2}$, and TMAX ${ }^{2} \cdot \mathrm{PRCP}^{2}$ are all included.

Panel (B) depicts the fact that all weather variables and their combinations from panel (A) are interacted with each of the terms listed in the "Season indicators" box, including a constant. Here $1\{$ winter $\}=1$ for observations occurring in winter. Thus, the set of variables in panel (B) includes, for example,

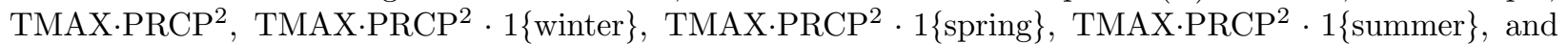
TMAX $\cdot \mathrm{PRCP}^{2} \cdot 1\{$ fall $\}$.

Finally, panel (C) illustrates that each of the variables included in panel (B) is interacted with a full set of region indicators, including a constant. Examples of variables the set depicted in panel (C) include TMAX, TMAX'PRCP ${ }^{2}$, TMAX·PRCP $2 \cdot 1$ summer\}, and TMAX·PRCP ${ }^{2} \cdot 1$ summer $\cdot 1$ \{Northeast\}.

Although this full set of variables contains up to 3,120 unique variable combinations, in practice there are fewer variables because for some of these combinations, such as SNOW·1\{summer\}, all observations equal zero.

The lasso of residuals on residuals (with cross validation) is performed twice, using the full set of variables depicted in this schematic separately for indoor stores and outdoor stores. 
Figure 2: Indoor and Outdoor Responses to Weather
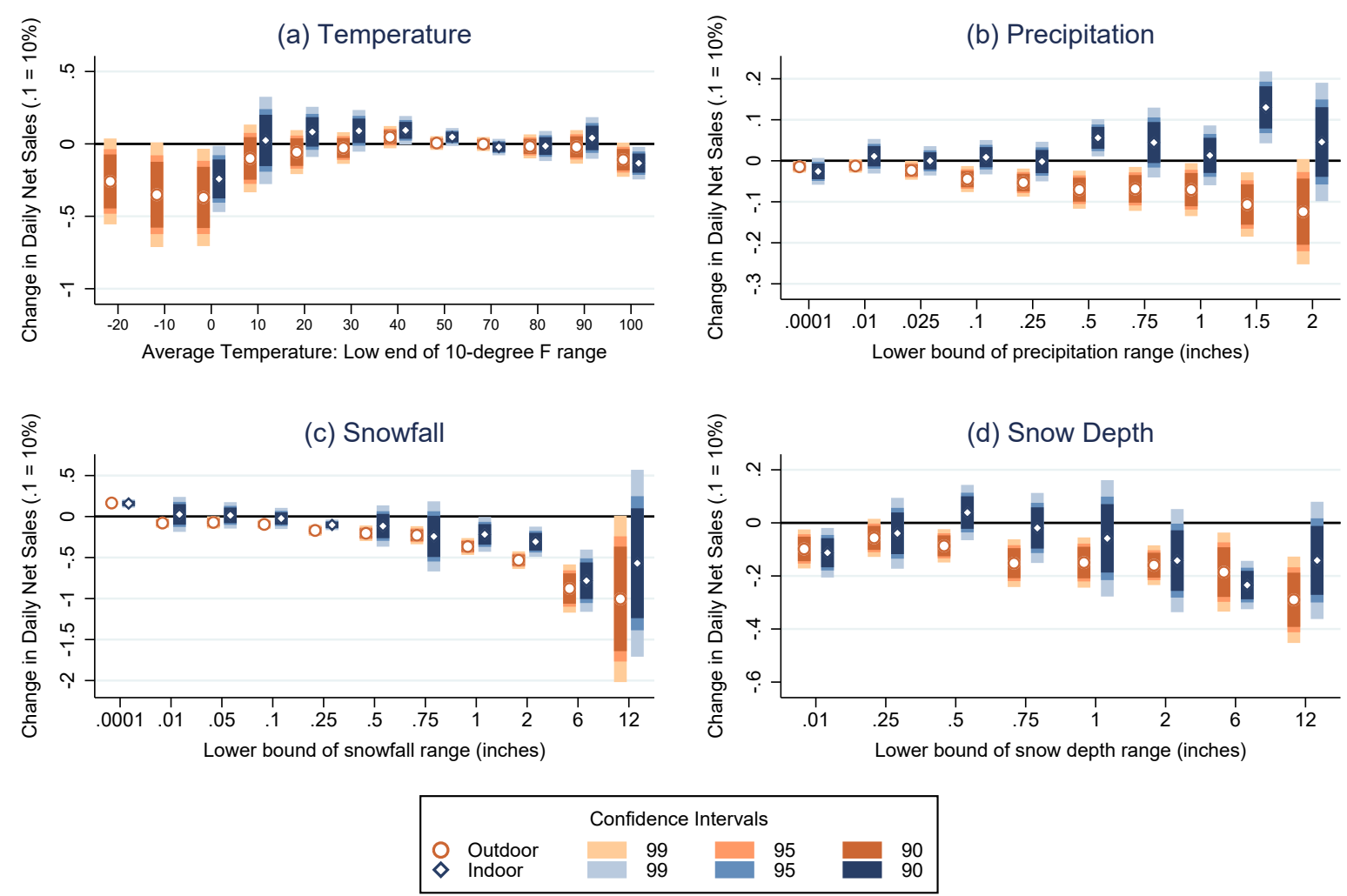

Note: Plots show results from regressing log of daily net store level sales on sets of indicators for non-parametric bins. "Indoor" stores are in shopping centers where patrons can move between stores without being exposed to weather. All regressions control for date, store-month, store-month, and store-day-of-week fixed effects as well as store-specific trends and indicators for store openings and closings. The regressions depicted in panel (a) further controls for precipitation, snowfall, and snow depth and shows effects relative to the base category of $60-70^{\circ} \mathrm{F}$, while panels (b)-(d) control for maximum temperature and show effects relative to zero precipitation, snowfall, and snow depth.

Source: Proprietary sales data; NOAA, National Centers for Environmental Information (NCEI). Global Historical Climatology Network Daily. (Accessed April 22, 2015.) 
Figure 3: Weather Effects on Online Sales

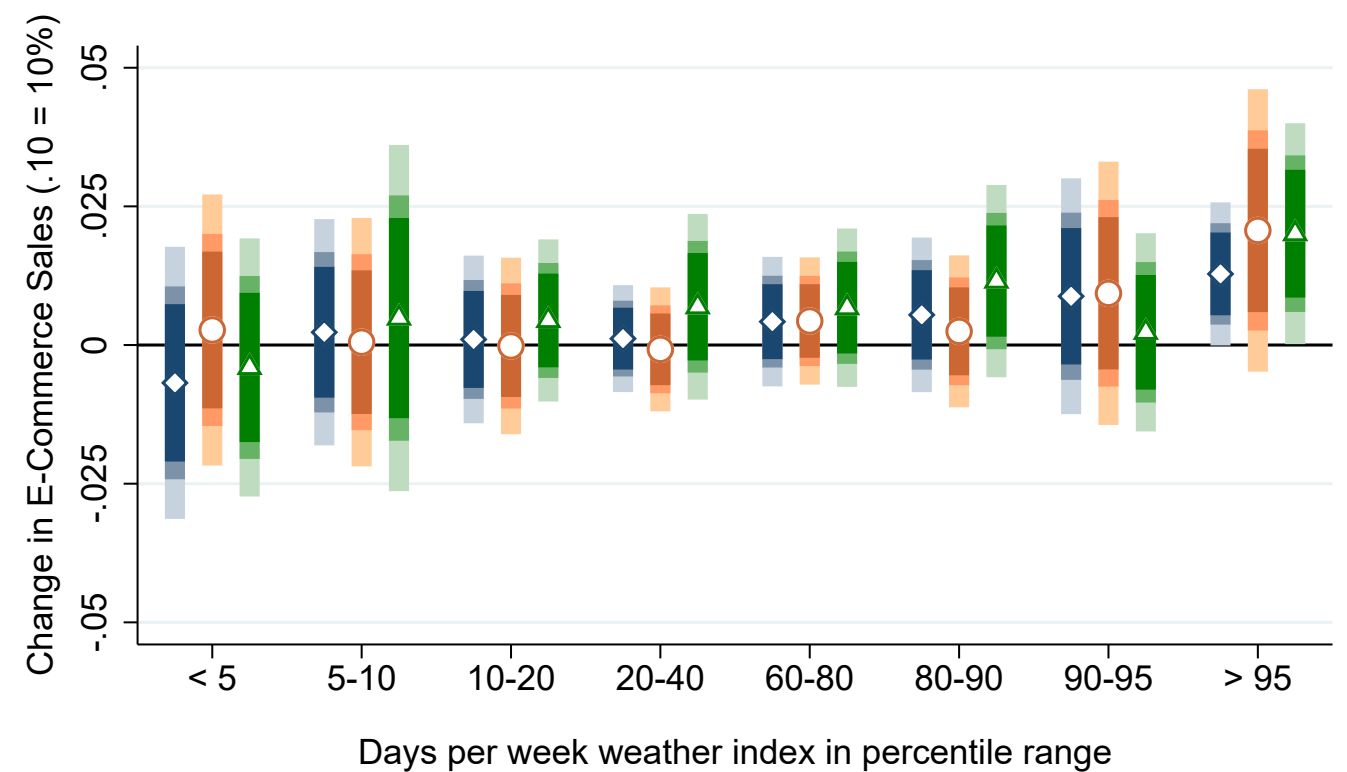

\begin{tabular}{|l|c|c|c|}
\hline \multicolumn{4}{|c|}{ Confidence Intervals } \\
$\diamond$ Indoor Index: & 99 & 95 & 90 \\
$\bigcirc$ Outdoor Index: & 99 & 95 & 90 \\
$\triangle$ Mean Index: & 99 & 95 & 90 \\
\hline
\end{tabular}

Note: This figure shows results from regressing sales on the firm's website for week $k$ in MSA $m$ on counts of the number of days in which the "weather index" falls within the noted ranges that week. The figure shows results from three separate regressions where the weather index is averaged over just indoor stores, just outdoor stores, or equally across the two types. With a mean of 0 and standard deviation of 1 , the weather index measures how favorable weather conditions are for sales. A more positive value corresponds to a more positive weather shock. Constructed using the lasso machine learning method with cross-validation in a residuals-on-residuals framework to select among thousands of potential interacted and non-linear weather variables, the index flexibly reflects the contemporaneous weather shock for a specific store on a specific day. "Indoor" stores are in shopping centers where patrons can move between stores without being exposed to weather. Regressions control for week and MSA-month fixed effects as well as MSA-specific linear and quadratic time trends, with standard errors clustered at the MSA and week levels.

Source: Proprietary sales data; NOAA, National Centers for Environmental Information (NCEI). Global Historical Climatology Network Daily. (Accessed April 22, 2015.) 
Figure 4: Cumulative Daily Effects of Weather Events

(a) Positive weather shocks

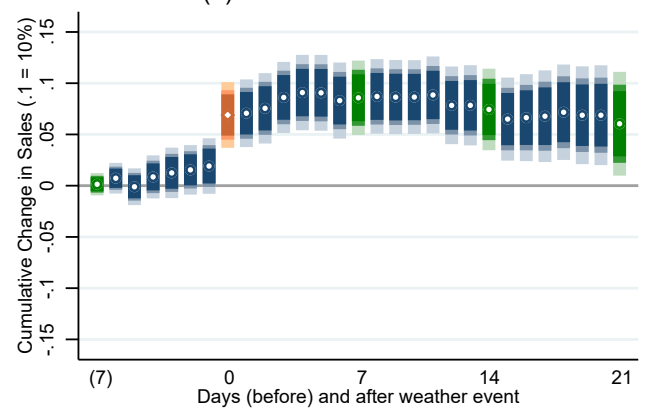

(c) Weather index value between 1 and 2

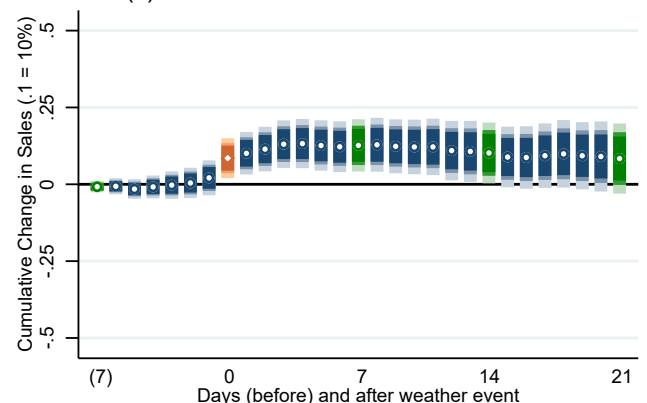

(e) Weather index value $>2$

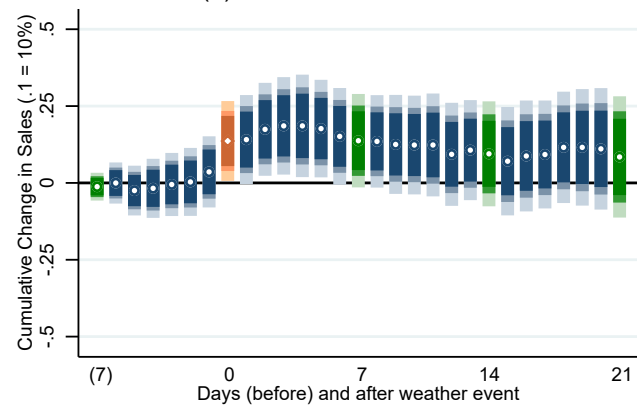

(b) Negative weather shocks

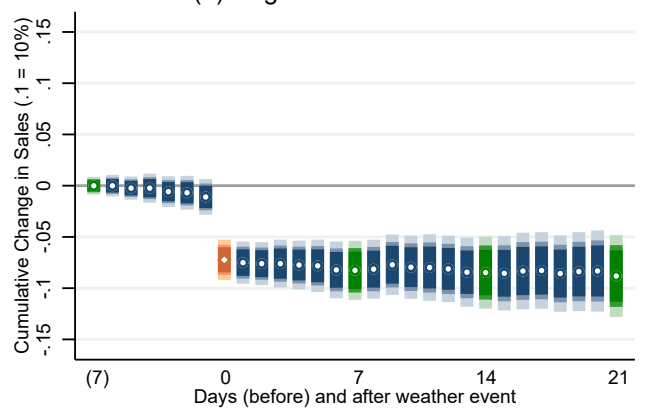

(d) Weather index value between -2 and -1

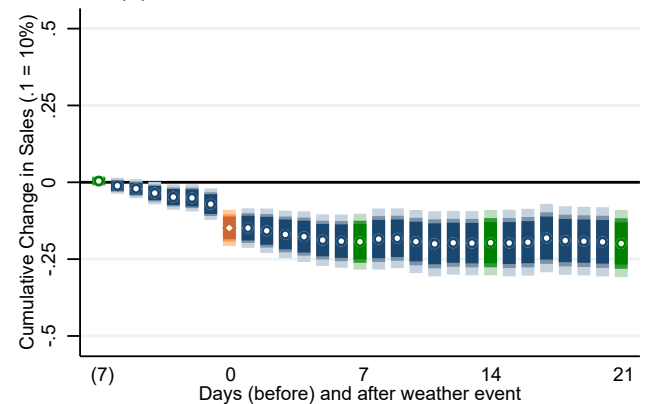

(f) Weather index value $<-2$

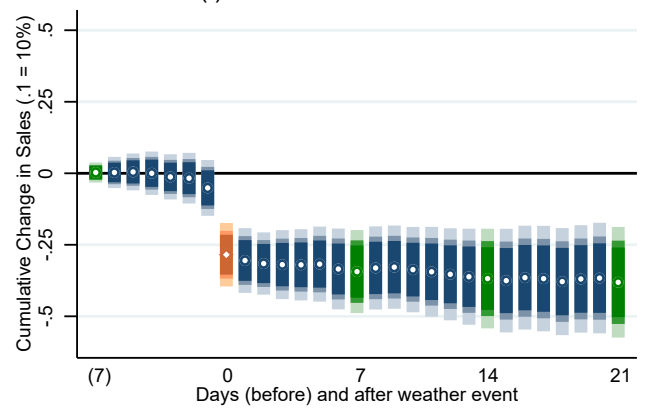

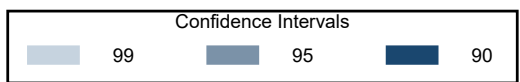

Note: Plots show cumulative results from regressing net sales at store $i$ on day $t=0$ on a series of leads and lags of weather shocks as measured by the "weather index." With a mean of 0 and standard deviation of 1 , the weather index measures how favorable weather conditions are for sales. A more positive value corresponds to a more positive weather shock. Constructed using the lasso machine learning method with cross-validation in a residuals-on-residuals framework to select among thousands of potential interacted and non-linear weather variables, the index flexibly reflects the contemporaneous weather shock for a specific store on a specific day. The cumulative results start seven days before the shock and go up to 21 days after a weather shock. Panels a and b show jointly estimated responses to continuous weather index values. Panels $\mathrm{c}-\mathrm{f}$ show jointly estimated responses to index values falling within particular ranges. Each regression controls for date, day-of-year, store-month, and store-day-of-week fixed effects as well as store-specific trends and indicators for store openings and closings. Standard errors have been clustered by MSA and date.

Source: Proprietary sales data; NOAA, National Centers for Environmental Information (NCEI). Global Historical Climatology Network Daily. (Accessed April 22, 2015.) 


\section{Appendix A}

Table A1: Summary Statistics for Current Weather

\begin{tabular}{|c|c|c|c|c|c|c|c|c|c|c|}
\hline & Mean & SD & Min & 5th pct & 25 th pct & Median & 75 th pct & 95th pct & $\operatorname{Max}$ & $\mathrm{N}$ \\
\hline \multicolumn{11}{|l|}{ Temperature } \\
\hline Max Temp (F) & 70.409 & 17.874 & -4.167 & 36.910 & 58.566 & 73.040 & 84.221 & 94.478 & 118.940 & 137,348 \\
\hline Avg Temp (F) & 61.002 & 16.947 & -11.106 & 30.456 & 49.271 & 63.249 & 74.564 & 84.195 & 104.990 & 137,259 \\
\hline Min Temp (F) & 51.594 & 16.686 & -23.086 & 23.000 & 39.407 & 53.345 & 65.047 & 75.060 & 94.540 & 137,343 \\
\hline TAVG $\geqslant 80 \mathrm{~F}$ & 0.131 & 0.338 & 0.000 & 0.000 & 0.000 & 0.000 & 0.000 & 1.000 & 1.000 & 137,259 \\
\hline TAVG $\geqslant 90 \mathrm{~F}$ & 0.010 & 0.097 & 0.000 & 0.000 & 0.000 & 0.000 & 0.000 & 0.000 & 1.000 & 137,259 \\
\hline $\mathrm{TMAX} \leqslant 0 \mathrm{C}$ & 0.027 & 0.162 & 0.000 & 0.000 & 0.000 & 0.000 & 0.000 & 0.000 & 1.000 & 137,348 \\
\hline $\mathrm{TAVG} \leqslant 15 \mathrm{~F}$ & 0.005 & 0.071 & 0.000 & 0.000 & 0.000 & 0.000 & 0.000 & 0.000 & 1.000 & 137,259 \\
\hline \multicolumn{11}{|l|}{ Precipitation } \\
\hline Precipitation (in) & 0.100 & 0.291 & 0.000 & 0.000 & 0.000 & 0.000 & 0.041 & 0.602 & 6.416 & 137,625 \\
\hline Positive precipitation & 0.399 & 0.490 & 0.000 & 0.000 & 0.000 & 0.000 & 1.000 & 1.000 & 1.000 & 137,625 \\
\hline $\mathrm{PRCP} \geqslant 1$ in & 0.021 & 0.145 & 0.000 & 0.000 & 0.000 & 0.000 & 0.000 & 0.000 & 1.000 & 137,625 \\
\hline $\mathrm{PRCP} \geqslant 2$ in & 0.004 & 0.060 & 0.000 & 0.000 & 0.000 & 0.000 & 0.000 & 0.000 & 1.000 & 137,625 \\
\hline Precipitation if positive & 0.252 & 0.418 & 0.000 & 0.002 & 0.017 & 0.086 & 0.311 & 1.036 & 6.416 & 54,858 \\
\hline \multicolumn{11}{|l|}{ Snowfall } \\
\hline Snowfall (in) & 0.039 & 0.385 & 0.000 & 0.000 & 0.000 & 0.000 & 0.000 & 0.000 & 17.350 & 137,911 \\
\hline Positive snowfall & 0.037 & 0.189 & 0.000 & 0.000 & 0.000 & 0.000 & 0.000 & 0.000 & 1.000 & 137,911 \\
\hline $\mathrm{SNOW} \geqslant 1$ in & 0.011 & 0.103 & 0.000 & 0.000 & 0.000 & 0.000 & 0.000 & 0.000 & 1.000 & 137,911 \\
\hline $\mathrm{SNOW} \geqslant 6$ in & 0.001 & 0.030 & 0.000 & 0.000 & 0.000 & 0.000 & 0.000 & 0.000 & 1.000 & 137,911 \\
\hline Snowfall if positive & 1.062 & 1.704 & 0.003 & 0.029 & 0.125 & 0.401 & 1.220 & 4.313 & 17.350 & 5,112 \\
\hline \multicolumn{11}{|l|}{ Snow Depth } \\
\hline Snow Depth (in) & 0.172 & 1.137 & 0.000 & 0.000 & 0.000 & 0.000 & 0.000 & 0.000 & 22.992 & 137,886 \\
\hline Positive snow depth & 0.048 & 0.214 & 0.000 & 0.000 & 0.000 & 0.000 & 0.000 & 0.000 & 1.000 & 137,886 \\
\hline SNWD $\geqslant 1$ in & 0.033 & 0.179 & 0.000 & 0.000 & 0.000 & 0.000 & 0.000 & 0.000 & 1.000 & 137,886 \\
\hline $\mathrm{SNWD} \geqslant 6$ in & 0.009 & 0.093 & 0.000 & 0.000 & 0.000 & 0.000 & 0.000 & 0.000 & 1.000 & 137,886 \\
\hline Snow depth if positive & 3.550 & 3.842 & 0.025 & 0.203 & 0.923 & 2.132 & 4.914 & 12.008 & 22.992 & 6,666 \\
\hline
\end{tabular}

Note: Observations span April 2010-December 2013. Observations are at the daily store level and equal the inverse distance weighted averages of weather observations from weather stations located at airports and weather forecast offices within 70 miles and 400 meters elevation of a given store. Stations missing more than 5 percent of precipitation or temperature observations between 2010 and 2013 have been dropped, yielding anywhere from one to seven weather stations to average over for each store. Missing values are imputed using OLS regressions on nearby weather station observations. Missing snowfall and snow depth observations have been replaced with zeros when national monthly snowfall maps indicate that there was no snow at the weather station locations in the applicable months.

Source: NOAA, National Centers for Environmental Information (NCEI). Global Historical Climatology Network Daily. (Accessed April 22, 2015.) 
Table A2: Summary Statistics for Historical Weather Variables

\begin{tabular}{|c|c|c|c|c|c|c|c|c|c|c|}
\hline & Mean & SD & Min & 5th pct & 25 th pct & Median & 75 th pct & 95th pct & $\operatorname{Max}$ & $\mathrm{N}$ \\
\hline \multicolumn{11}{|l|}{ Temperature } \\
\hline Normal Max Temp (F) $\left(\mu_{i d}^{T M A X}\right)$ & 69.365 & 16.165 & 22.082 & 39.171 & 58.279 & 72.025 & 82.007 & 90.683 & 106.994 & 138,026 \\
\hline Std Dev Max Temp $(\mathrm{F})\left(\sigma_{i d}^{T M A X}\right)$ & 7.530 & 2.368 & 1.518 & 3.506 & 5.912 & 7.373 & 9.340 & 11.409 & 14.101 & 138,026 \\
\hline Normal Min Temp $(\mathrm{F})\left(\mu_{i d}^{T M I N}\right)$ & 50.433 & 15.278 & 3.773 & 23.688 & 39.226 & 51.724 & 62.792 & 73.358 & 83.705 & 138,026 \\
\hline Std Dev Min Temp $(\mathrm{F})\left(\sigma_{i d}^{T M I N}\right)$ & 6.542 & 2.448 & 1.468 & 2.698 & 4.717 & 6.457 & 8.319 & 10.469 & 14.982 & 138,026 \\
\hline $\mathrm{P}(\mathrm{TAVG} \geqslant 80 \mathrm{~F})$ & 0.104 & 0.121 & 0.001 & 0.006 & 0.018 & 0.046 & 0.143 & 0.347 & 0.423 & 138,026 \\
\hline $\mathrm{P}(\mathrm{TAVG} \geqslant 90 \mathrm{~F})$ & 0.006 & 0.025 & 0.000 & 0.000 & 0.000 & 0.000 & 0.001 & 0.013 & 0.230 & 138,026 \\
\hline $\mathrm{P}(\mathrm{TMAX} \leqslant 0 \mathrm{C})$ & 0.040 & 0.049 & 0.000 & 0.000 & 0.000 & 0.014 & 0.064 & 0.136 & 0.213 & 138,026 \\
\hline $\mathrm{P}(\mathrm{TAVG} \leqslant 15 \mathrm{~F})$ & 0.011 & 0.019 & 0.000 & 0.000 & 0.000 & 0.002 & 0.014 & 0.045 & 0.122 & 138,026 \\
\hline \multicolumn{11}{|l|}{ Precipitation } \\
\hline Normal Precipitation (in) $\left(\mu_{i d}^{P R C P}\right)$ & 0.101 & 0.054 & 0.000 & 0.006 & 0.073 & 0.108 & 0.129 & 0.191 & 0.349 & 138,026 \\
\hline Std Dev Precipitation (in) $\left(\sigma_{i d}^{\psi_{R C P}}\right)$ & 0.285 & 0.131 & 0.002 & 0.046 & 0.211 & 0.299 & 0.361 & 0.497 & 0.846 & 138,026 \\
\hline Normal PRCP if positive (in) & 0.117 & 0.051 & 0.000 & 0.032 & 0.093 & 0.115 & 0.135 & 0.229 & 0.349 & 55,259 \\
\hline Std dev PRCP if positive (in) & 0.314 & 0.115 & 0.002 & 0.127 & 0.248 & 0.312 & 0.376 & 0.517 & 0.834 & 55,259 \\
\hline $\mathrm{P}(\mathrm{PRCP} \geqslant 1$ in $)$ & 0.025 & 0.013 & 0.000 & 0.004 & 0.015 & 0.027 & 0.033 & 0.043 & 0.056 & 138,026 \\
\hline $\mathrm{P}(\mathrm{PRCP} \geqslant 2$ in $)$ & 0.005 & 0.004 & 0.000 & 0.000 & 0.002 & 0.004 & 0.007 & 0.012 & 0.019 & 138,026 \\
\hline \multicolumn{11}{|l|}{ Snowfall } \\
\hline Normal Snowfall (in) $\left(\mu_{i d}^{S N O W}\right)$ & 0.042 & 0.102 & 0.000 & 0.000 & 0.000 & 0.000 & 0.015 & 0.273 & 0.958 & 138,026 \\
\hline Std Dev Snowfall (in) $\left(\sigma_{i d}^{i d N O W}\right)$ & 0.177 & 0.343 & 0.000 & 0.000 & 0.000 & 0.000 & 0.173 & 1.006 & 2.395 & 138,026 \\
\hline$\mu_{i d}^{S N O W}$ if positive (in) & 0.288 & 0.173 & 0.000 & 0.025 & 0.167 & 0.272 & 0.384 & 0.598 & 0.958 & 5,227 \\
\hline$\sigma_{i d}^{S N O W}$ if positive (in) & 0.913 & 0.370 & 0.000 & 0.215 & 0.718 & 0.962 & 1.107 & 1.475 & 2.395 & 5,227 \\
\hline $\mathrm{P}(\mathrm{SNOW} \geqslant 1$ in $)$ & 0.012 & 0.014 & 0.000 & 0.000 & 0.000 & 0.005 & 0.017 & 0.040 & 0.067 & 138,026 \\
\hline $\mathrm{P}(\mathrm{SNOW} \geqslant 6$ in $)$ & 0.001 & 0.001 & 0.000 & 0.000 & 0.000 & 0.001 & 0.002 & 0.003 & 0.007 & 138,026 \\
\hline \multicolumn{11}{|l|}{ Snow Depth } \\
\hline Normal Snow Depth (in) $\left(\mu_{i d}^{S N W D}\right)$ & 0.171 & 0.594 & 0.000 & 0.000 & 0.000 & 0.000 & 0.012 & 1.108 & 7.001 & 138,026 \\
\hline Std Dev Snow Depth (in) $\left(\sigma_{i d}^{S N W D}\right)$ & 0.341 & 0.822 & 0.000 & 0.000 & 0.000 & 0.000 & 0.147 & 2.332 & 7.102 & 138,026 \\
\hline$\mu_{i d}^{S N W D}$ if positive (in) & 1.759 & 1.483 & 0.000 & 0.122 & 0.692 & 1.253 & 2.484 & 4.917 & 7.001 & 6,806 \\
\hline$\sigma_{i d}^{S N W D}$ if positive (in) & 2.531 & 1.299 & 0.000 & 0.603 & 1.604 & 2.482 & 3.190 & 4.847 & 7.102 & 6,806 \\
\hline $\mathrm{P}(\mathrm{SNWD} \geqslant 1$ in $)$ & 0.032 & 0.045 & 0.000 & 0.000 & 0.000 & 0.007 & 0.040 & 0.141 & 0.208 & 138,026 \\
\hline $\mathrm{P}(\mathrm{SNWD} \geqslant 6$ in $)$ & 0.009 & 0.017 & 0.000 & 0.000 & 0.000 & 0.001 & 0.009 & 0.047 & 0.098 & 138,026 \\
\hline
\end{tabular}

Note: Shares of historical observations above particular thresholds are labeled as $P(E L E M \geqslant X)$, where $X$ is the threshold in question. TAVG and TMAX refer to the average and maximum daily temperatures, respectively. Observations are based on weather from 1980-2009. Observations are reported at the daily store level, though the historical share variables do not vary over time for any given store. Each observation equals the inverse distance weighted average of the corresponding normals, standard deviations, or shares at airports and weather forecast office weather stations within 70 miles and 400 meters elevation of a given store. Normals and standard deviations have been calculated using a Bartlett weighting kernel over a 29-day period to smooth over observations, and thus vary over the course of the calendar year. In the case where a weather station has only 10-15 years of historical data, the Bartlett weighting kernel averages over a 43-day window. Stations with fewer than 10 years of historical data were dropped. Missing precipitation, snowfall, and snow depth observations have been replaced with zeros.

Source: NOAA, National Centers for Environmental Information (NCEI). Global Historical Climatology Network Daily. (Accessed April 22, 2015.) 
Figure A1: Weather observations by climate region

(a) Temperature

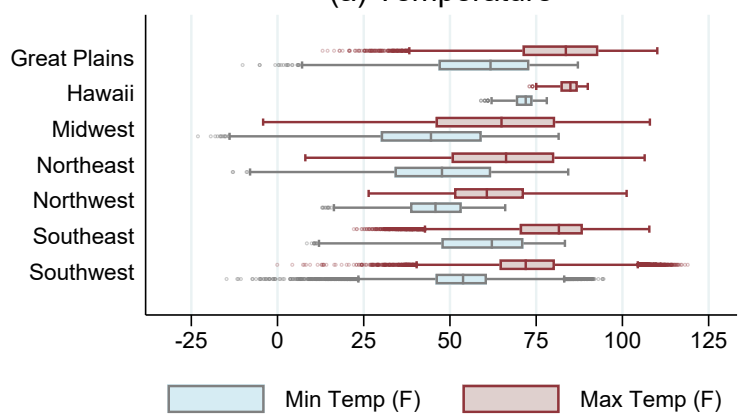

(c) Snowfall

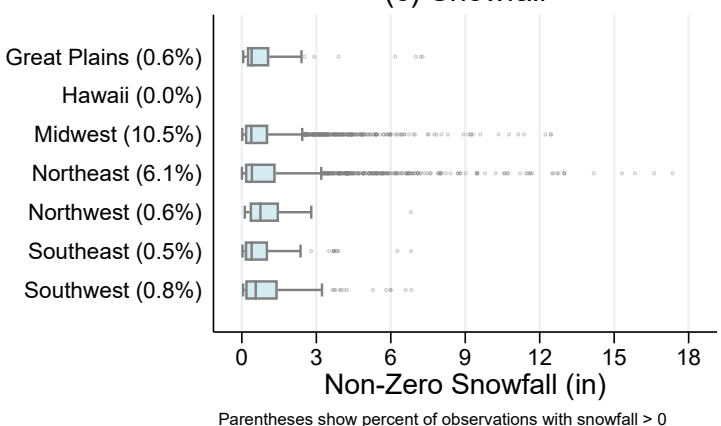

(b) Precipitation

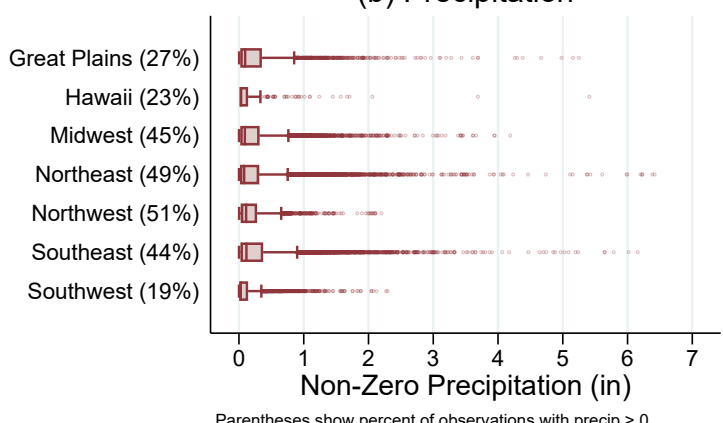

(d) Snow depth

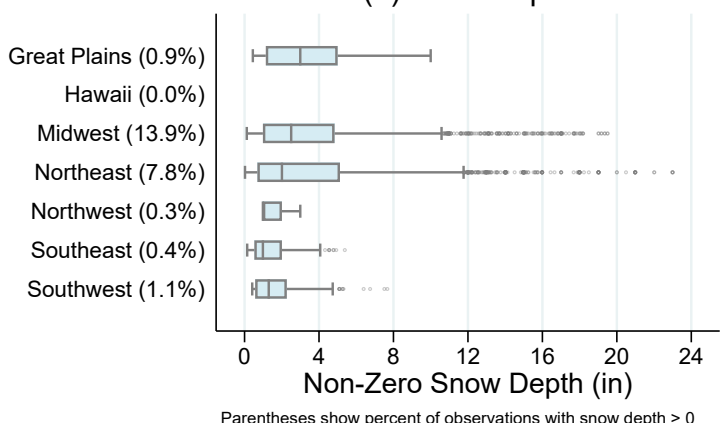

Note: Plots show regional heterogeneity of distributions of observed weather. For precipitation, snowfall, and snow depth, box plots show distributions of non-zero observations and percentages in parentheses next to region names indicate the fraction of days with positive observations.

Source: NOAA, National Centers for Environmental Information (NCEI). Global Historical Climatology Network Daily. (Accessed April 22, 2015.)

Interpretation: The stores in the data are in regions exhibiting a wide range of climates. 
Figure A2: Temperature Effects by Season

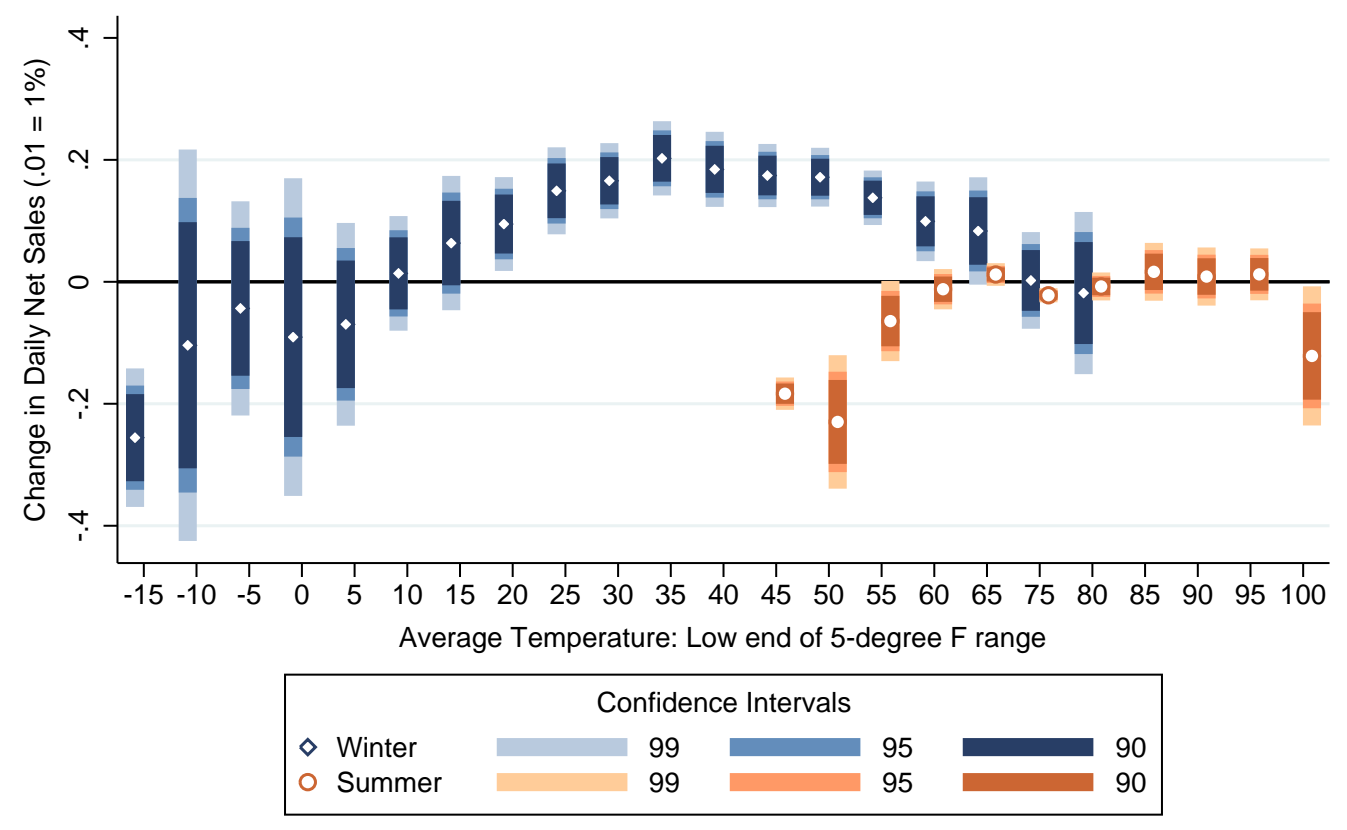

Note: This figure shows results from regressing log of daily net store level sales on sets of indicators for non-parametric temperature bins. The effects shown are relative to the omitted base category of $70-75^{\circ} \mathrm{F}$. Winter is defined as December February, and summer is defined as June - August. The regressions control for precipitation, snowfall, and snow depth as well as date, store-month, store-month, and store-day-of-week fixed effects, store-specific trends, and indicators for store openings and closings.

Source: Proprietary sales data; NOAA, National Centers for Environmental Information (NCEI). Global Historical Climatology Network Daily. (Accessed April 22, 2015.) 
Figure A3: Weather Index Illustration
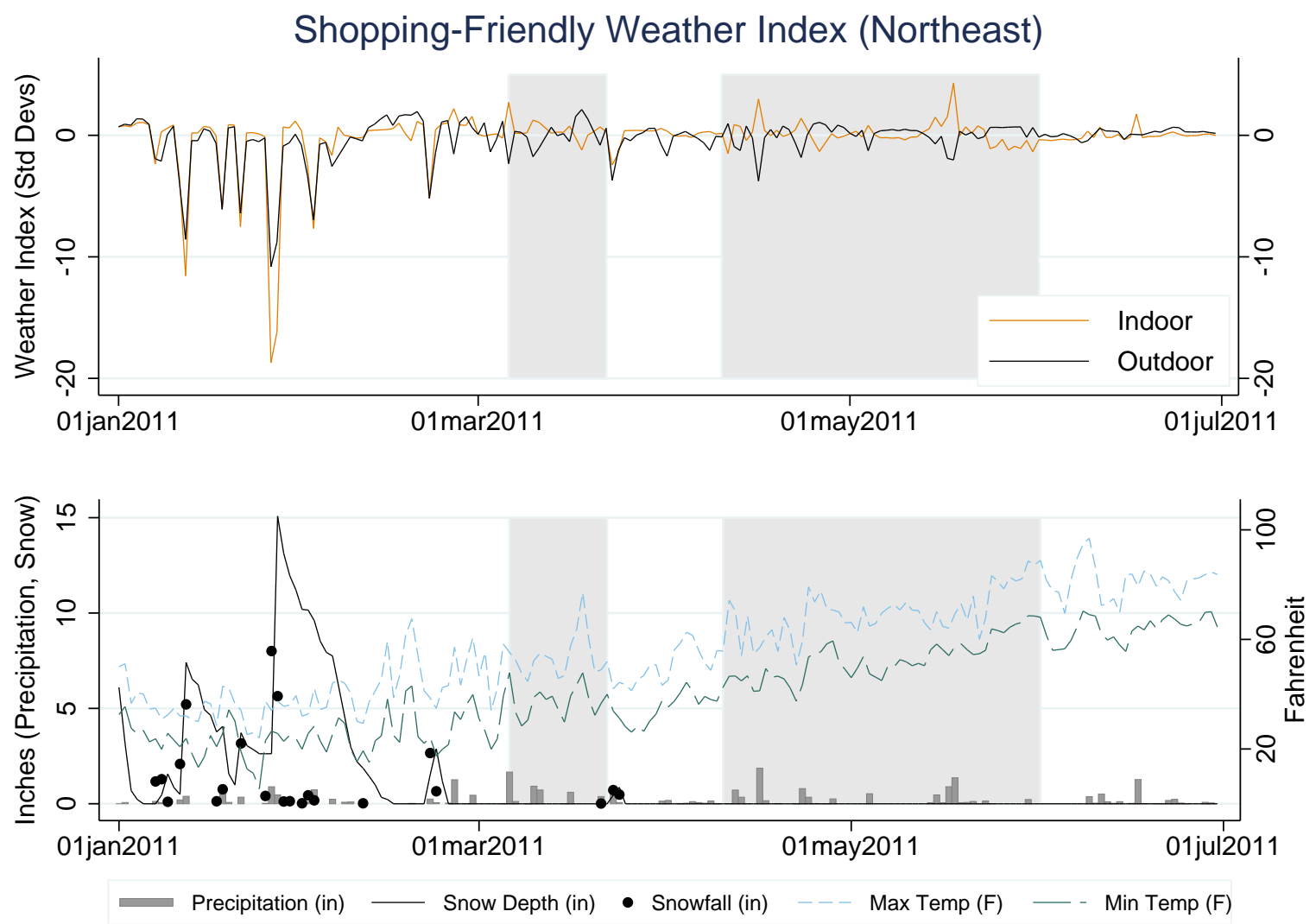

Note: The upper panel shows for a city in the Northeast the indoor and outdoor "weather index." With a mean of 0 and standard deviation of 1 , the weather index measures how favorable weather conditions are for sales. A more positive value corresponds to a more positive weather shock. Constructed using the lasso machine learning method with cross-validation in a residuals-on-residuals framework to select among thousands of potential interacted and non-linear weather variables, the index flexibly reflects the contemporaneous weather shock for a specific store on a specific day. "Indoor" stores are in shopping centers where patrons can move between stores without being exposed to weather. The gray shading highlights the periods during which the indoor and outdoor weather indexes are negatively correlated. The lower panel shows observed weather.

Source: Proprietary sales data; NOAA, National Centers for Environmental Information (NCEI). Global Historical Climatology Network Daily. (Accessed April 22, 2015.) 
Figure A4: Non-Cumulative Daily Effects of Weather Events on Surrounding Days

(a) Positive weather shocks

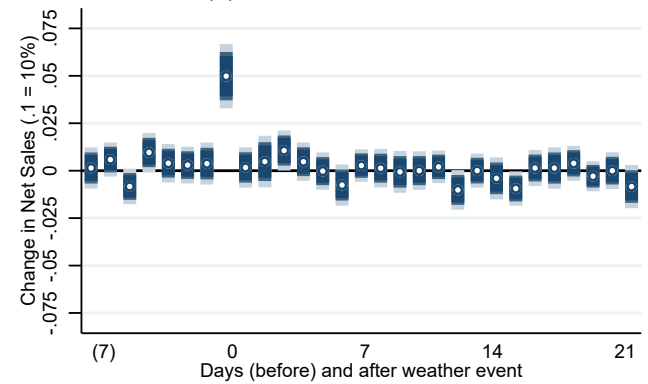

(c) Weather index value between 1 and 2

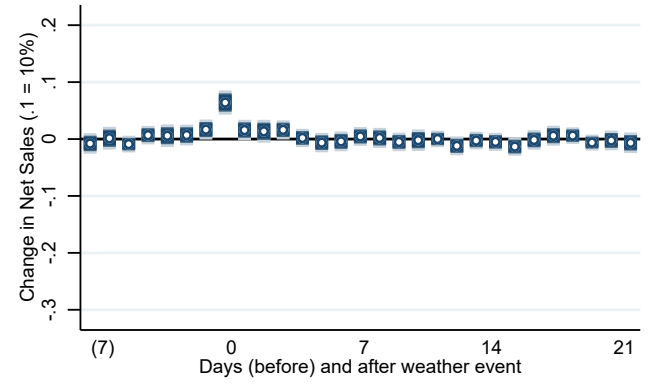

(e) Weather index value $>2$

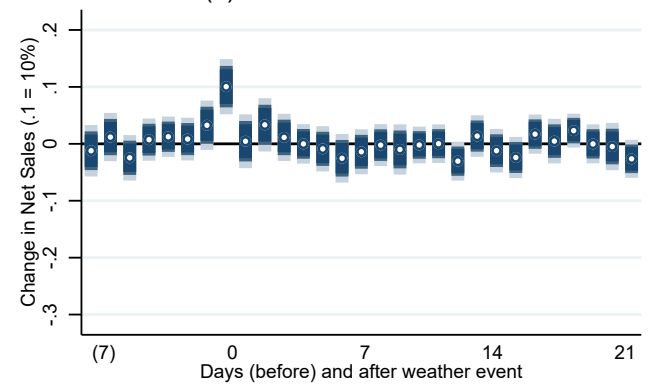

(b) Negative weather shocks

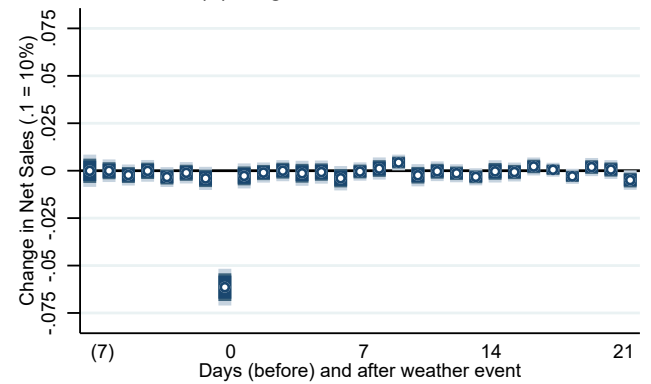

(d) Weather index value between -1 and -2

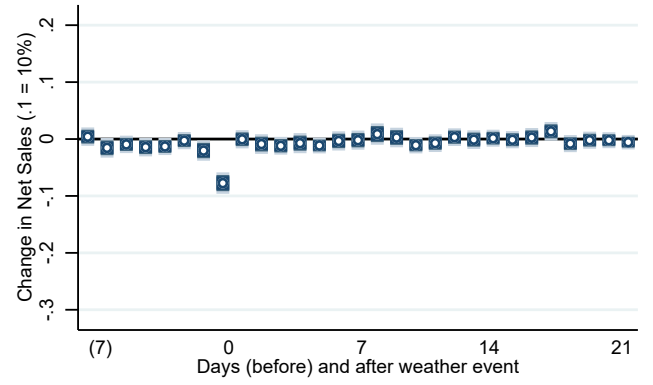

(f) Weather index value $<-2$

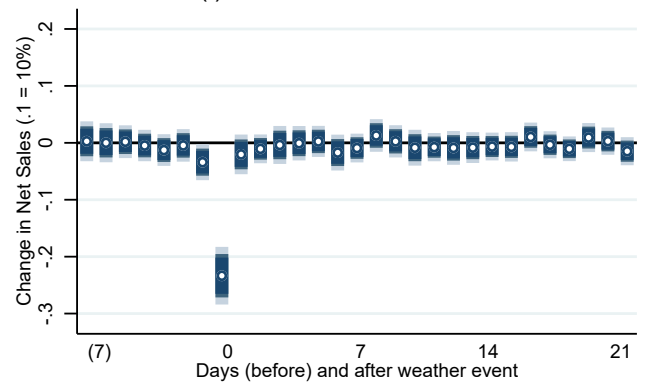

Confidence Intervals

99

90

Note: Plots show non-cumulative results from regressing net sales at store $i$ on day $t=0$ on a series of leads and lags of weather shocks as measured by the "weather index." With a mean of 0 and standard deviation of 1 , the weather index measures how favorable weather conditions are for sales. A more positive value corresponds to a more positive weather shock. Constructed using the lasso machine learning method with cross-validation in a residuals-on-residuals framework to select among thousands of potential interacted and non-linear weather variables, the index flexibly reflects the contemporaneous weather shock for a specific store on a specific day. Panels a and b show jointly estimated responses to continuous weather index values. Panels $\mathrm{c}-\mathrm{f}$ show jointly estimated responses to index values falling within particular ranges. Each regression controls for date, day-of-year, store-month, and store-day-of-week fixed effects as well as store-specific trends and indicators for store openings and closings. Standard errors have been clustered by MSA and date.

Source: Proprietary sales data; NOAA, National Centers for Environmental Information (NCEI). Global Historical Climatology Network Daily. (Accessed April 22, 2015.) 
Figure A5: Placebo Test Results Based on Shuffling Months

(a) Intertemporal, indoor vs. outdoor, and online responses

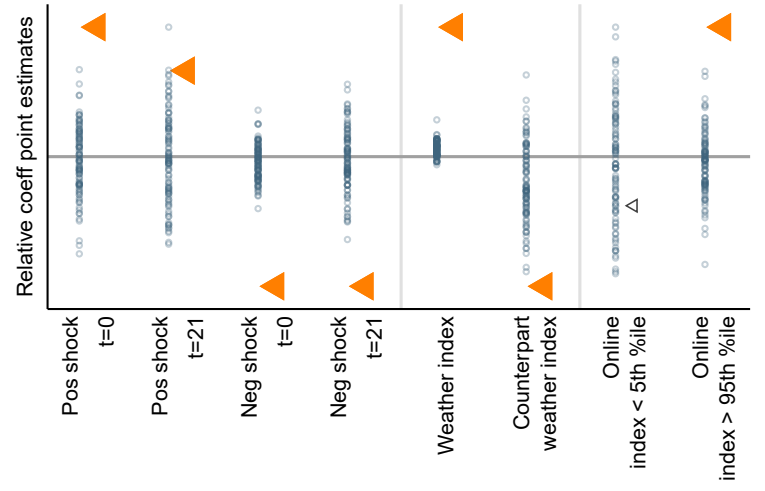

(c) Adaptation to weather normals \& std devs (Table 3, col 3)

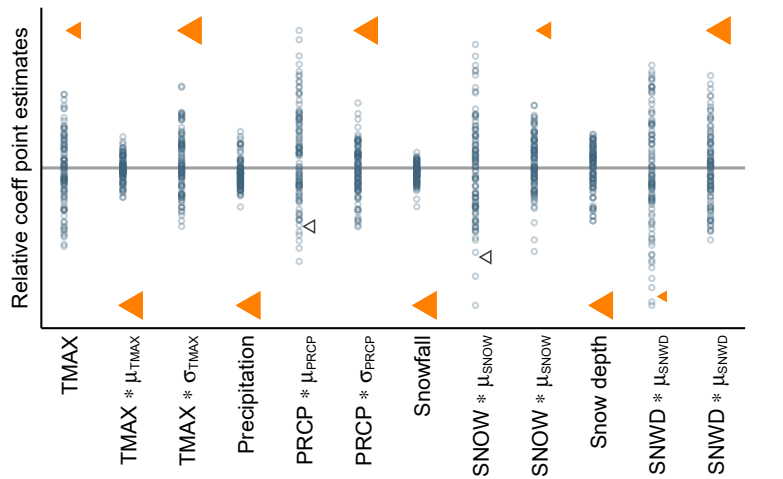

(b) Adaptation to weather normals (Table 3, column 2)

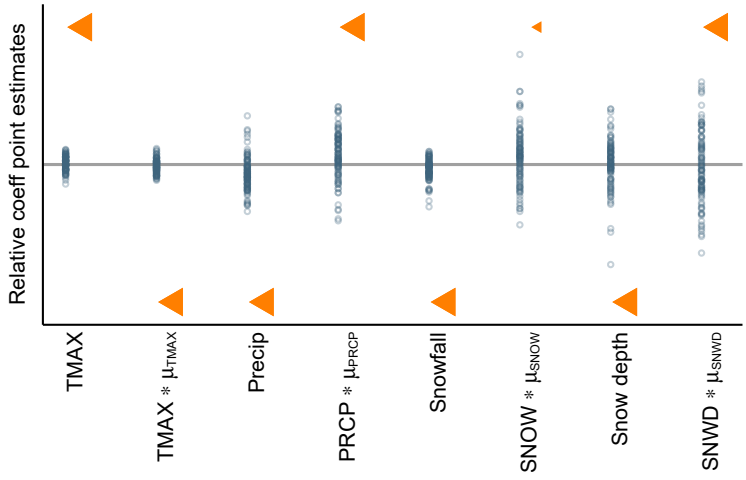

(d) Adaptation to weather events (Table 4, col 2)

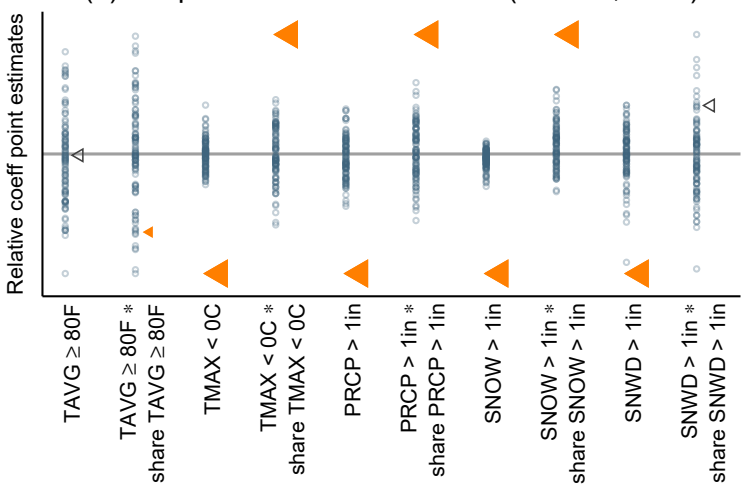

\section{Statistical significance of coefficient estimated using real data \\ $\triangleleft$ Insignificant $\triangleleft 90 \%$ level \\ $95 \%$ level \\ $99 \%$ level}

Note: Panels compare distributions of placebo estimation results (blue circles) with coefficient estimates based on real data (triangles). The placebo results are based on 100 simulations in which the weather variables have been reshuffled by randomizing their month and year. The y-axes have been rescaled by dividing the individual coefficient estimates by the maximum absolute value of a coefficient estimate for the given variable (the maximum over both the placebo and real data.) Panel (a) includes coefficients from Figure 4 (panels a and b), Table 1 (column 1), and Figure 3 (the Mean Index). The size of each triangle indicates the statistical significance of the coefficients in the estimates using the real data as presented in the main body of the paper. The horizontal line indicates 0 .

Source: Proprietary sales data; NOAA, National Centers for Environmental Information (NCEI). Global Historical Climatology Network Daily. (Accessed April 22, 2015.) 
Figure A6: Placebo Test Results Based on Shuffling Locations

(a) Intertemporal, indoor vs. outdoor, and online responses

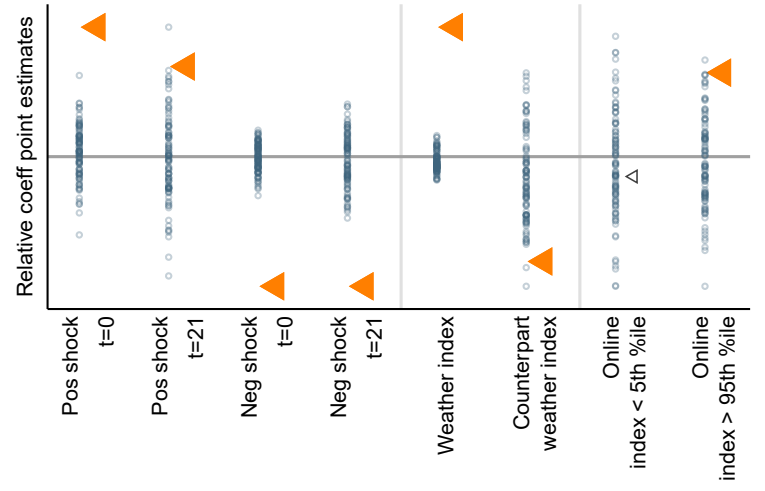

(c) Adaptation to weather normals \& std devs (Table 3, col 3)

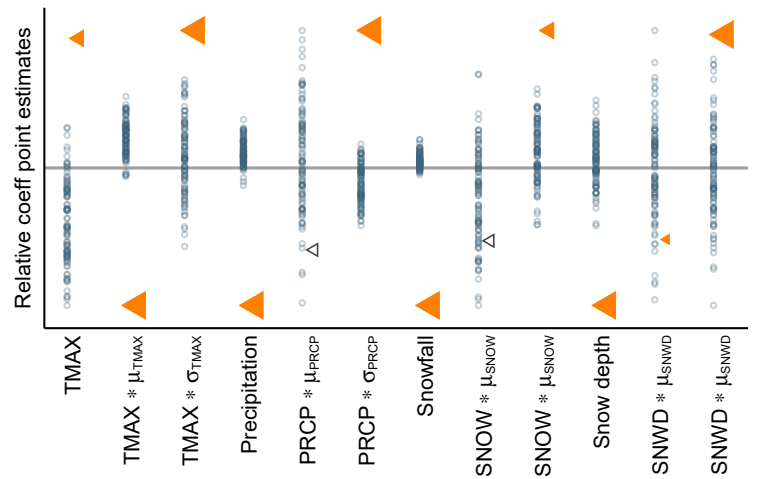

(b) Adaptation to weather normals (Table 3, column 2)

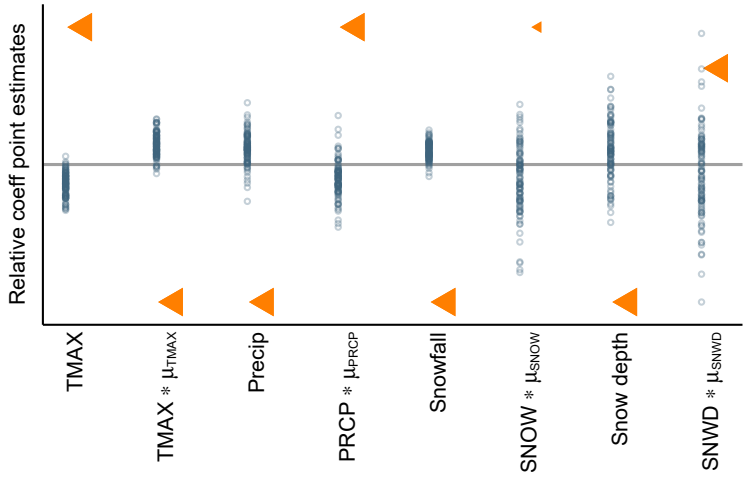

(d) Adaptation to weather events (Table 4, col 2)

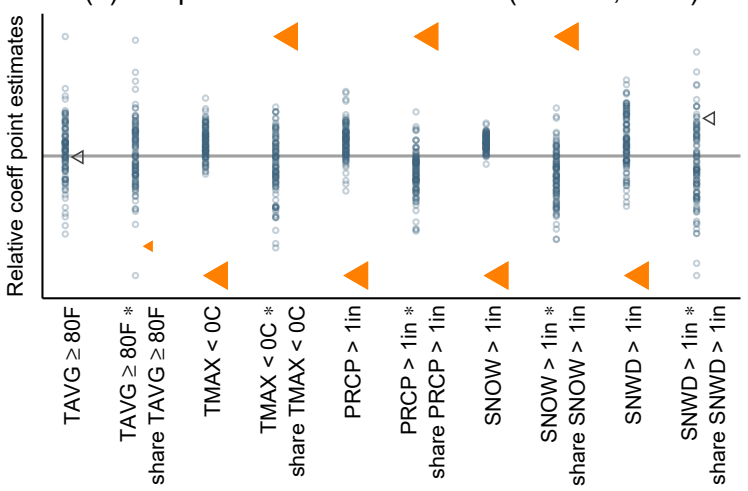

\section{Statistical significance of coefficient estimated using real data \\ $\triangleleft$ Insignificant $\triangleleft 90 \%$ level \\ 95\% level \\ $99 \%$ level}

Note: Panels compare distributions of placebo estimation results (blue circles) with coefficient estimates based on real data (triangles). The placebo results are based on 100 simulations in which the weather variables have been reshuffled by randomizing their location. The y-axes have been rescaled by dividing the individual coefficient estimates by the maximum absolute value of a coefficient estimate for the given variable (the maximum over both the placebo and real data.) Panel (a) includes coefficients from Figure 4 (panels a and b), Table 1 (column 1), and Figure 3 (the Mean Index). The size of each triangle indicates the statistical significance of the coefficients in the estimates using the real data as presented in the main body of the paper. The horizontal line indicates 0 .

Source: Proprietary sales data; NOAA, National Centers for Environmental Information (NCEI). Global Historical Climatology Network Daily. (Accessed April 22, 2015.) 